\title{
VELEBITSKE PTICE
}

Gordan Lukač

Marijan Milovac

Nikica Bušljeta

Ivana Adžić

Natalija Andačić

Javna ustanova Nacionalni park Paklenica

Dr. Franje Tuđmana 14a

HR 23244 Starigrad Paklenica

sluzba-zastite@paklenica.hr

Snježana Vujčić-Karlo

Narodni muzej Zadar, Prirodoslovni odjel

Medulićeva 2

HR 23000 Zadar

prirodoslovni.odjel@nmz.hr

Willibald Stani

Peltztmannstrasse 17

A 8435 Wagna
UDK: 598.2(234 Velebit)

Pregledni članak

Ur.: 2017-01-31

Istraživanja ornitofaune južnog dijela Velebita odvijaju se kontinuirano od 1984. god. do danas. Dio podataka je prikupljen promatranjem ptica u različitim dijelovima NP Paklenica, ali i na dijelovima južnog Velebita, od Velikog Libinja do Tulovih greda, Prezida i Crnopca. Područje srednjeg Velebita istraživano je od Bačić kose do Alaginca i Bačić kuka 2003. god., te povremeno 2011. i 2012. god. Područje sjevernog Velebita posjećivano je oko Zavižana, botaničkog vrta, dijela Premužićeve staze do Rossijeve kolibe, Lomske dulibe i Štirovače tjekom 1988. god. i povremeno od 2007. do 2011. god. Ptice su bilježene u vrijeme gniježđenja, proljetne i jesenske selidbe kao i zimi. Do sada je na Velebitu zabilježena 271 vrsta ptica.

Unutar granica NP Paklenica obitava 165 vrsta, od kojih se gnijezdi 101 vrsta. U području NP Sjeverni Velebit je zabilježeno 110 vrsta ptica. Danas se sa sigurnošću može reći da se 127 vrsta ptica gnijezdi na planini Velebit. Ovaj prilog sadrži cjeloviti popis zabilježenih vrsta ptica, kategorije ugroženosti, sezonski status, kao i procjenu brojnosti gnjezdarica, odnosno preletnica.

Ključne riječi: velebitske ptice, ptice gnjezdarice, bogatstvo i raznolikost vrsta, brojnost, tipovi staništa, PP Velebit, NP Paklenica, NP Sjeverni Velebit, krš 


\section{Uvod}

Popisi ptica naših zaštićenih područja postoje u većini nacionalnih parkova i parkova prirode. ${ }^{1} \mathrm{U}$ pojedinim nacionalnim parkovima i parkovima prirode liste ptica se nadopunjuju, odvijaju se ornitološka istraživanja i monitoring pojedinih vrsta ili skupina.

Na području Velebita, najbolje su istražene ptice NP Paklenica. One i ptice šire okolice obrađene su u prilozima o promatranju ptica, kao i nalazima prepariranih ptica ulovljenih u različitim dijelovima Velebita, a danas čuvanih u prirodoslovnim zbirkama Zavoda za ornitologiju HAZU i Hrvatskog prirodoslovnog muzeja u Zagrebu. ${ }^{2}$ U NP Paklenica obitava 165 vrsta, od kojih se 101 vrsta gnijezdi, dok je na širem području NP Paklenica do kraja 2016. god zabilježeno 260 ptičjih vrsta. Širi prostor Parka podrazumijeva obalni dio od Šibuljine, preko Starigrada-Paklenice, Selina, pa do Modriča. U popis vrsta su uvrštena opažanja drugih ornitologa i promatrača za koje je utvrđeno da su pouzdani i dobro raspoznaju vrste. Tijekom zadnjih 20 -ak godina terenska istraživanja ovog prostora i detaljnije kartiranje omogućilo je utvrđivanje još nekih vrsta na gniježđenju, odnosno na selidbi u obalnom području. U ovom prilogu se daje popis zabilježenih vrsta ptica, a u tijeku je prikupljanje podataka o gniježđenju pojedinih vrsta, tipu staništa, njihovoj brojnosti u pojedinim dijelovima Velebita, o pravcima selidbe na širem prostoru parka prirode. Ovaj prilog trebao bi poslužiti kao osnova za daljnja praćenja promjena u brojnosti pojedinih rijetkih i ugroženih ptičjih vrsta, posebno ptica grabljivica, sova, djetlića, ptica dupljašica, poludupljašica te malobrojnih vrsta gnjezdarica čija će se brojnost najvjerojatnije mijenjati uslijed pojačanog posjećivanja pojedinih dijelova ili uslijed globalnih

${ }^{1}$ G. LUKAČ - T. MIKUSKA, 2007, 357-370; G. LUKAČ - S. VUJČIĆ-KARLO - W. STANI - D. MARGUŠ, 2015, 1-532.

2 V.R. TSCHUSI ZU SCHMIDHOFFEN, 1890, 66-68; M. MAREK, 1901, 43-66; 1904, 31-61; 1905, 76-104; M. HIRTZ, 1912, 16-37; 1914, 1-15; 1915, 74-90; 1936, 161-230; A. MAŠTROVIĆ, 1942, 1-192; M. MAŠTROVIĆ, 1947, 36-56; J. REICHHOLF, 1977, 1-28; G. SUŠIĆ - D. RADOVIĆ - V. BARTOVSKY, 1988, 37-88; M. STIPČEVIĆ - G. LUKAČ, 1991, 37-49; G. LUKAČ - M. STIPČEVIĆ - R. CRNKOVIĆ - D. BEM, 1992, 81-91; G.LUKAČ - M. STIPČEVIĆ, 1997, 11-60; G. LUKAČ, 1998, 1-160.; 1999, 1-23.; 2000, 26-36; D. RUCNER, 1998, 1-311; M. STIPČEVIĆ - G. LUKAČ, 2001, 9-21; M. KATIĆ, 2002, 1-93; G. LUKAČ M. STIPČEVIĆ - R. HAUPT, 2003, 51-59; G. LUKAČ, 2004, 95-104; 2004a, 105-112; 2004b, 141-146; 2004c, 151-154; 2004d, 161-166; 2004e, 167-170; 2004f, 113-122; 2007, 1-147; 2007a, 32-35; I. GRBAC - J. KRALJ, 2008, 1-226; G. LUKAČ, 2011, 1-356; G. LUKAČ - S. VUJČIĆKARLO - M. MILOVAC - I. ADŽIĆ, 2016, 7-16. 
klimatskih promjena, odnosno većih zahvata u južnom Velebitu, planiranog skijališta i novih šumskih putova. Raznolikost djetlića i sjenica u šumskim ekosustavima ukazuje na starost i vrijednost šumskih staništa u čitavom Velebitu. Na području NP Sjeverni Velebit posebno su u posljednjih 10ak godina uočeno sušenje smrekovih šuma, što je vjerojatno pridonijelo opadanju raznolikosti pojedinih ptičjih vrsta u takvim, osušenim sastojinama. Stoga, navedene vrste kao kokoške, sove, djetlići, grmuše i sjenice, mogu biti odlični bioindikatori stanja šumskih ekosustava. U pojedinim dijelovima srednje Europe su lještarka i tetrijeb indikatori kvalitete i očuvanosti šumskih staništa ${ }^{3}$. U Velebitu je to prije svega veliki tetrijeb koji je još uvijek gnjezdarica sjevernog i srednjeg dijela (Rukavina usmeno).

\section{Materijal i metode rada}

Popis ptica sastavljen je na temelju tridesetdvogodišnjih promatranja ptica na području NP Paklenica, NP Sjeverni Velebit, Baških Oštarija, Dabarskih kukova, područja Tulovih greda, Prezida i Crnopca. Brojnost pojedinih vrsta i njihova rasprostranjenost na Velebitu utvrđena je tijekom terenskih istraživanja provedenih u razdoblju od 1984. do 1995, god. Dio terenskih podataka za NP Paklenicu su iznijeti u prilogu o pticama NP Paklenica $^{4}$. Precizniji podatci o brojnosti i rasprostranjenosti pojedinih vrsta dobiveni su terenskim izlascima u sezoni gniježđenja tijekom 1992. samo za vršni dio južnog Velebita te od 1996. do 2016, tijekom kartiranja NP Paklenica, Tab. 1 i 2. Istraživanja su se odvijala u svim sezonama ${ }^{5}$ (Tab. 3). Brojnost šumskih i livadnih vrsta istraživana je metodom transekata u proljeće - od druge dekade ožujka pa do kraja prve dekade srpnja - a nastojalo se obuhvatiti sve tipove vegetacije. Transekti su rađeni po tipovima staništa i nezavisno od kartiranja ${ }^{6}$. Tijekom istraživanja su napravljena 273 transekta (Tab. 4). U razdoblju od 1996. do 2016. godine redovito su rađeni i transekti u kanjonu Velike i Male Paklenice radi usporedbe bogatstva i raznolikosti ptičjih zajednica, radi praćenja utjecaja posjećivanja i posjetitelja na ornitofaunu. Redovito su kanjoni obilaženi u sezoni gniježđenja (od kraja ožujka do početka srpnja) radi utvrđivanja brojnosti pojedinih vrsta ptica

\footnotetext{
${ }^{3}$ S. KLAUS, 1995, 11-21; S. KLAUS - U. AUGST, 1995, 109-123.

${ }^{4}$ G. LUKAČ - M. STIPČEVIĆ, 1997, 11-60.

${ }^{5} \mathrm{G}$. LUKAČ, 2011, 1-356.

${ }^{6}$ M.L. CODY, 1985, 1-558; M. FLADE, 1994, 1-250; C.J. BIBBY - N.D. BORGES - D.A. HILL, 1992, 1-257.
} 
gnjezdarica tijekom desetogodišnjeg/dvadesetogodišnjeg razdoblja radi utvrđivanja eventualnih nepovoljnih utjecaja posjetitelja, posebno penjača ${ }^{7}$.

U južnom dijelu Velebita također su dobro istraženi dijelovi od Modriča prema Tulovim gredama, Sv. Roku, Crvenim potocima, Miloj Vodi i Prezidu. U srednjem dijelu Velebita je obilažen dio oko Ljubičkog brda uz potok Ljubicu, Bačić kosa i kukovi od Bačić kose do tunela uz cestu. U sjevernom dijelu je istraživan NP Sjeverni Velebit kod Zavižana, botaničkog vrta u Modriča docu i staza do Rossijeve kolibe. U obalnom dijelu je istraživanje izvođeno kod Jablanca, Zavratnice, Karlobaga, Tribanj Šibuljine i Ljubotića.

Najslabije su istraženi dijelovi oko Crnopca, jugoistočni Velebit, kao i sjeverne padine Velebita od Visočice do Zavižana na sjeverozapad i na jugoistok od Tribnja do Baških Oštarija.Tijekom istraživanja 2014. i 2015. god. posebna pažnja je posvećena monitoringu ptica grabljivica, prvenstveno sivog sokola (Falco peregrinus), orla zmijara (Circaetus gallicus), eji livadarki (Circus pygargus), surom orlu (Aquila chrysaetos), vjetruši (Falco tinnunculus) i kopcu (Accipiter nisus). Osim u NP Paklenica, istraživanja su proširena na južne dijelove PP Velebit, Tulove grede, Prezid i pojedine dijelove ispod Crnopca. Srednji dio Velebita je povremeno istraživan na Baškim M.L. Oštarijama, Bačić kosi, do Bačić kuka i Prikinutog brda. Pri istraživanju sova posebna se pažnja usmjerila na ušaru (Bubo bubo), oko ulaznih dijelova Velike i Male Paklenice koji su obilaženi noću i koji su dostupni cestom. Pri tome je bilježena brojnost ćuka (Otus scops) i sivog ćuka (Athene noctua).

$\mathrm{U}$ istom razdoblju su napravljeni transekti na Velikom i Malom Rujnu za česte vrste. Ukupna duljina transekata je $5.400 \mathrm{~m}$, a podatci su sakupljeni metodom prebrojavanja (census) u točki.

Ptice gnjezdarice su istraživane po visinskom gradijentu. Ptice preletnice (selice) i vrste izvan perioda gniježđenja (zimovalice) istraživane su od mjeseca srpnja do kraja mjeseca svibnja. Pojedine vrste selile su i tijekom lipnja. Posebno je veliki broj izlazaka ostvaren u obalnom području, u vrijeme proljetne i jesenske selidbe, te zimi. Istaknuta mjesta preleta ili zadržavanja ptica su uvala Jaz (ušće potoka Velika Paklenica) i uvala Modrič. U vršnoj zoni je najmanji broj terenskih izlazaka ostvaren zimi, tek nekoliko, zbog ekstremnih zimskih uvjeta što iziskuje posebnu opremu i boravak u zimskim uvjetima.

Broj terenskih izlazaka po pojedinim mjesecima na području NP Paklenica je vidljiv iz Tab. 1. Tijekom kartiranja u sezoni gniježđenja, u proljeće i jesen za selidbe, te zimi na terenu se boravilo ukupno 2207 terenskih dana tijekom gotovo 22 godine u pojedinim dijelovima PP Velebit (Sl. 1, Tab. 1).

\footnotetext{
${ }^{7}$ G. LUKAČ - V. HRŠAK, 2005, 186-199.
} 
Tab. 1. Broj terenskih dana po pojedinim godinama i mjesecima na području NP Paklenica.

\begin{tabular}{|l|r|r|r|r|r|r|r|r|r|r|r|r|r|}
\hline Mjesec & I. & II. & III. & IV. & V. & VI. & VII. & VIII. & IX. & X. & XI. & XII. & Ukupno \\
\hline Godina & & & & & & & & & & & & & \\
\hline 1992. & & - & & - & - & 15 & 15 & & - & - & - & - & 30 \\
\hline 1995. & & - & & - & - & - & 9 & 15 & 9 & 10 & 3 & 15 & 61 \\
\hline 1996. & 17 & 12 & 10 & 8 & 17 & 6 & 5 & 10 & 6 & 10 & 4 & 4 & 109 \\
\hline 1997. & 9 & 5 & 6 & 12 & 15 & 7 & 13 & 9 & 8 & 13 & 13 & 9 & 119 \\
\hline 1998. & 7 & 8 & 6 & 10 & 11 & 21 & 10 & 7 & 6 & 6 & 4 & 16 & 112 \\
\hline 1999. & 5 & 7 & 4 & 6 & 9 & 7 & 14 & 9 & 14 & 15 & 17 & 4 & 111 \\
\hline 2000. & 14 & 7 & 11 &. .15 & 17 & 12 & 10 & 9 & 18 & 15 & 12 & 14 & 154 \\
\hline 2001. & 19 & 7 & 12 &. .12 & 12 & 11 & 9 & 16 & 16 & 16 & 13 & 16 & 159 \\
\hline 2002. & 9 & 2 & 5 &. .13 & 18 & 6 & 4 & 10 & 15 & 14 & 18 & 11 & 125 \\
\hline 2003. & 12 & 11 & 16 &. .10 & 11 & 9 & 10 & 11 & 12 & 10 & 15 & 6 & 133 \\
\hline 2004. & 10 & 8 & 7 &. .11 & 12 & 10 & 10 & 11 & 11 & 15 & 8 & 9 & 122 \\
\hline 2005. & 8 & 9 & 20 &. .16 & 18 & 16 & 10 & 12 & 11 & 7 & 13 & 9 & 149 \\
\hline 2006. & 12 & 8 & 10 &. .15 & 16 & 7 & 8 & 5 & 5 & 8 & 5 & 6 & 106 \\
\hline 2007. & 6 & 4 & 18 &. .11 & 8 & 9 & 6 & 5 & 5 & 5 & 5 & 6 & 89 \\
\hline 2008. & 8 & 6 & 10 &. .12 & 9 & 9 & 10 & 16 & 15 & 16 & 17 & 14 & 142 \\
\hline 2009. & 10 & 13 & 12 &. .12 & 12 & 10 & 6 & 5 & 4 & 3 & $3-$ & $3-$ & 93 \\
\hline 2010. & 3 & 4 & 4 & 5 & 5 & 6 & 5 & 4 & 3 & 4 & 4 & 4 & 51 \\
\hline 2012. & 3 & 4 & 4 & 5 & 5 & 6 & 4 & 4 & 4 & 5 & 6 & 5 & 55 \\
\hline 2013. & 3 & 4 & 6 & 6 & 5 & 3 & 3 & 4 & 3 & 3 & 4 & 4 & 48 \\
\hline 2014. & 3 & 4 & 5 & 5 & 5 & 6 & 4 & 4 & 4 & 4 & 3 & 3 & 49 \\
\hline 2015. & 3 & 4 & 4 & 5 & 5 & 6 & 6 & 5 & 5 & 4 & 4 & 3 & 55 \\
\hline 2016. & 3 & 2 & 3 & 3 & 4 & 5 & 5 & 3 & 3 & 4 & 3 & 1 & 40 \\
\hline Ukupno & 164 & 123 & 166 & 194 & 177 & 167 & 171 & 171 & 174 & 183 & 171 & 161 & 2112 \\
\hline
\end{tabular}

Tab. 2. Broj terenskih dana u pojedinim dijelovima NP Paklenica u proteklom razdoblju istraživanja.

\begin{tabular}{|l|r|r|r|r|r|r|}
\hline Područje Parka & $\begin{array}{c}\text { Lička } \\
\text { padina }\end{array}$ & $\begin{array}{c}\text { Vršna } \\
\text { zona }\end{array}$ & $\begin{array}{r}\text { Centralni } \\
\text { dio Parka }\end{array}$ & Kanjoni & Obalni dio & Ukupno \\
\hline Broj terenskih dana & 32 & 100 & 430 & 1001 & 549 & 2112 \\
\hline
\end{tabular}

Tab. 3. Terenski izlasci u sjeverni, srednji i jugoistočni dio Velebita

\begin{tabular}{|l|r|r|r|r|r|}
\hline Dio Velebita & \multicolumn{1}{|c|}{ sjeverni } & \multicolumn{1}{c|}{ srednji } & južni & jugoistočni & ukupno \\
\hline Broj terenskih dana & 30 & 35 & 2112 & 30 & 2207 \\
\hline
\end{tabular}


Tab. 4 Broj napravljenih transekata na pojedinim lokalitetima tijekom istraživanja

\begin{tabular}{|l|c|}
\hline & Broj transekata \\
\hline Kanjon Velike Paklenice & 105 \\
\hline Kanjon Male Paklenice & 85 \\
\hline Vršni dio Velebita & 10 \\
\hline Centralni dio nacionalnog parka Paklenica & 9 \\
\hline Malo Libinje & 11 \\
\hline Veliko Rujno & 9 \\
\hline Veliko Libinje & 6 \\
\hline Tulove grede & 20 \\
\hline Mila Voda & 10 \\
\hline Prezid & 8 \\
\hline Ukupno & 273 \\
\hline
\end{tabular}

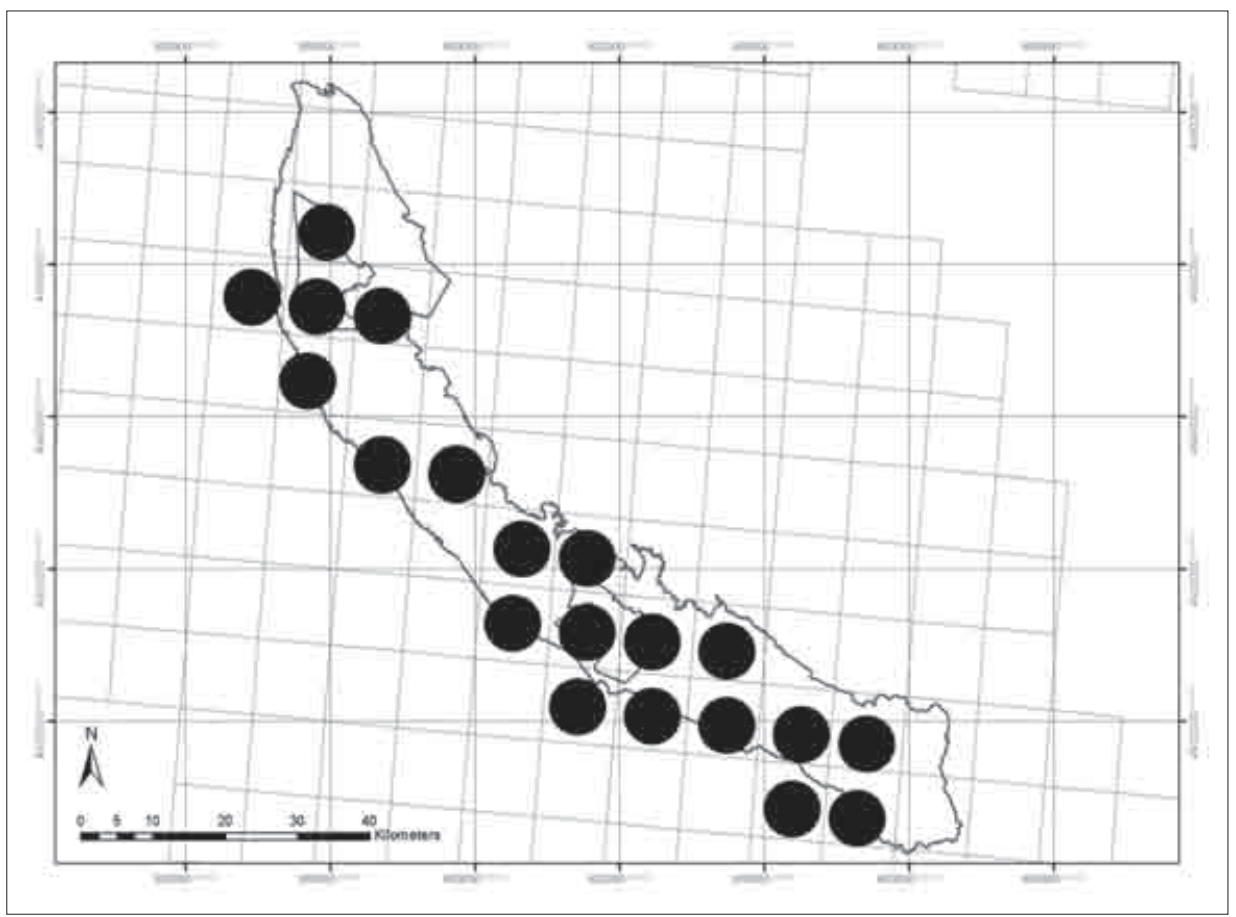

Sl. 1. Područje istraživanja u granicama PP Velebit, NP Sjeverni Velebit i NP Paklenica. 


\section{Rezultati rada}

Tijekom terenskih istraživanja u različitim područjima Velebita zabilježena je 271 vrsta ptica. Od toga je 127 vrsta ptica gnjezdarica i 93 vrste razvrstanih unutar različitih kategorija ugroženosti prema Crvenoj knjizi Ptica Hrvatske. Unutar granica NP Paklenica obitava 165 vrsta, od kojih se gnijezdi 101 vrsta. U NP Sjeverni Velebit je zabilježeno 110 vrsta ptica.

Sezonski status vrsta je preuzet prema Hagemeijer \& Blair i Lukaču\&. Pojedine vrste imaju više statusa, jer se pojavljuju i kao selice (PM), zimovalice (WV) ili ljetni gosti (SV).

$\mathrm{R}$ - resident - gnjezdarica stanarica;

$\mathrm{r}$ - resident - stanarica s manjim vertikalnim kretanjima;

$\mathrm{SV}$ - summer visitor - gnjezdarica selica;

sv- summer visitor - preletnica, ne gnijezdi;

$\mathrm{WV}$ - winter visitor - zimovalica;

$\mathrm{PM}$ - passge migrant - selica;

V - vagrant - rjeđa vrsta, zabilježena 4-6 puta;

RV - rare visitor - rijetka vrsta zabilježena 1-3 puta;

Status gnjezdarica je usvojen prema Sharrocku i i Hagemeijer \& Blair ${ }^{9}$.

A(1-2) - moguće gniježđenje;

B(3-9) - vjerojatno gniježđenje;

$\mathrm{C}(10-15)$ - gniježđenje je potvrđeno.

Tip staništa: 1- obala mora; 2-morska površina; 3-oranice i šumarci; 3a - šumarci alpeskog bora; 4- kamenjari; 5- šumarci hrasta medunca i bjelograba; 6- litice i stijene; 7- svi tipovi bukovih šuma; 7a- miješane šume bukve, jele i smreke; 8- šume crnog bora; 9- krške udoline (500-900 m); 10- visokoplaninske livade (1100-1700 m); 11- šume bora krivulja; 12 - naselja; 13 gorski potoci; 14 livade; 15 - obale rijeka.

Brojnost označava procijenjeni broj parova na Velebitu. Broj u zagradi označava brojnost primjeraka zabilježenih na jesenskom i proljetnom preletu ili tijekom zimovanja. Ptice gnjezdarice su u Tab. 5 označene zadebljalim slovima (bold).

${ }^{8}$ W. HAGEMEIJER- M. BLAIR, 1997, 1-903; G. LUKAČ, 2007, 1-147.

${ }^{9}$ T. J. SHARROCK, 1976, 1-477. 
Tab. 5. Popis ptičjih vrsta zabilježenih na Velebitu, prema literaturnim podatcima i vlastitim terenskim istraživanjima. Navedeno je ime vrste, status, stanište, procijenjena brojnost parova na gniježđenju (bez zagrade) ili jedinki na preletu ili zimovanju (vrijednosti u zagradi) te kategorija ugroženosti po populacijama. Debelim slovima su otisnute ptice gnjezdarice.

\begin{tabular}{|c|c|c|c|c|c|c|c|c|}
\hline \multirow{2}{*}{$\begin{array}{l}\text { Red. } \\
\text { Broj }\end{array}$} & \multirow{2}{*}{$\begin{array}{l}\text { Latinsko ime } \\
\text { vrste }\end{array}$} & \multirow{2}{*}{ Hrvatsko ime } & \multirow{2}{*}{ Status } & \multirow{2}{*}{ Stanište } & \multirow{2}{*}{$\begin{array}{l}\text { Brojnost, } \\
\text { parovi, } \\
\text { jedinke }\end{array}$} & \multicolumn{3}{|c|}{ Ugroženost } \\
\hline & & & & & & $\operatorname{Pr}$ & gn & $\mathbf{Z}$ \\
\hline 1. & Cygnus olor & $\begin{array}{l}\text { Crvenokljuni } \\
\text { labud }\end{array}$ & WV, sv & 2 & $(1-7)$ & & LC & \\
\hline 2. & C. cygnus & Žutokljuni labud & RV & 2 & (1) & & & \\
\hline 3. & Anser albifrons & Lisasta guska & RV & 1 & $(1-44)$ & $\mathrm{Lc}$ & & $\mathrm{Lc}$ \\
\hline 4. & Tadorna tadorna & Morska utva & RV & 2 & $(24-200)$ & $\mathrm{Lc}$ & & \\
\hline 5. & Anas penelope & Patka zviždara & WV & 1 & $(1-21)$ & $\mathrm{Lc}$ & & $\mathrm{Lc}$ \\
\hline 6. & A. strepera & $\begin{array}{l}\text { Patka } \\
\text { kreketaljka }\end{array}$ & RV & 1 & (8) & & $\mathrm{EN}$ & \\
\hline 7. & A. crecca & Patka kržulja & WV & 1 & $(2-4)$ & Lc & & Lc \\
\hline 8. & A. platyrhynchos & Divlja patka & WV,sv & 1 & $(1-165)$ & Lc & & \\
\hline 9. & A. acuta & Patka lastarka & WV & 1 & $(5-6)$ & Lc & $\mathrm{RE}$ & \\
\hline 10. & A. querquedula & Patka pupčanica & PM & 1 & $(1-100)$ & $\mathrm{Lc}$ & $\mathrm{Nt}$ & \\
\hline 11. & Spatula clypeata & Patka žličarka & PM & 1 & $(2-13)$ & Lc & $\mathrm{RE}$ & \\
\hline 12. & Netta rufina & Patka gogoljica & PM & 1 & $(1-2)$ & & $\mathrm{VU}$ & \\
\hline 13. & Aythya ferina & Glavata patka & PM,WV & 1,2 & $(1-17)$ & NA & Lc & NA \\
\hline 14. & A. nyroca & Patka njorka & PM & 1 & (1) & NA & $\mathrm{Nt}$ & NA \\
\hline 15. & A. fuligula & Krunata patka & PM,WV & 1 & $(1-8)$ & NA & $\mathrm{Nt}$ & NA \\
\hline 16. & A. marila & Patka crninka & WV & 2 & $(1-2)$ & & & \\
\hline 17. & $\begin{array}{l}\text { Clangula } \\
\text { hyemalis }\end{array}$ & Patka ledara & RV & 1 & (1) & & & \\
\hline 18. & Melanitta nigra & Crna patka & RV & 1 & $(1-3)$ & & & \\
\hline 19. & M. fusca & Patka kulašica & WV & 1 & $(1-7)$ & & & \\
\hline 20. & $\begin{array}{l}\text { Bucephala } \\
\text { clangula }\end{array}$ & $\begin{array}{l}\text { Patka } \\
\text { batoglavica }\end{array}$ & PM, WV & 1 & $(1-19)$ & Lc & & \\
\hline 21. & Mergus serrator & Mali ronac & PM, WV & 1 & $(2-30)$ & Lc & Lc & $\mathrm{Lc}$ \\
\hline 22. & M. merganser & Veliki ronac & WV & 1 & $(1-2)$ & & CR & \\
\hline 23. & Bonasa bonasia & Lještarka & $\mathbf{R}$ & 5 & $\begin{array}{l}120-150 \\
(120-150)\end{array}$ & & $\mathrm{Nt}$ & \\
\hline 24. & Tetrao urogallus & $\begin{array}{l}\text { Teterijeb } \\
\text { gluhan }\end{array}$ & $\mathbf{R}$ & 8,9 & $20-30$ & & EN & \\
\hline 25. & $\begin{array}{l}\text { Francolinus } \\
\text { francolinus }\end{array}$ & Crni frankolin & $\mathrm{R}$ & 4 & (1) & & & \\
\hline
\end{tabular}




\begin{tabular}{|c|c|c|c|c|c|c|c|c|}
\hline 26. & Alectoris graeca & \begin{tabular}{|l|} 
Jarebica \\
kamenjarka
\end{tabular} & R C12 & $4,5,8$ & $1200-1900$ & & $\mathrm{Nt}$ & \\
\hline 27. & A. chukar & Čukar & $\mathrm{R}$ & 9 & 1 & & & \\
\hline 28. & Perdix perdix & Trčka & $\mathrm{RV}$ & 3 & (1) & & $\mathrm{Nt}$ & \\
\hline 29. & Coturnix coturnix & Prepelica & PM A2 & 9 & $(1-3)$ & Lc & Lc & \\
\hline 30. & $\begin{array}{l}\text { Phasianus } \\
\text { colchicus }\end{array}$ & Fazan & R C 15 & 3,4 & $1-5$ & & Lc & \\
\hline 31. & Gavia stellata & $\begin{array}{l}\text { Crvenogrli } \\
\text { plijenor }\end{array}$ & WV & 2 & $(1-2)$ & Lc & & Lc \\
\hline 32. & G. arctica & $\begin{array}{l}\text { Crnogrli } \\
\text { plijenor }\end{array}$ & $\mathrm{PM}, \mathrm{WV}$ & 2 & $(1-30)$ & Lc & & Lc \\
\hline 33. & $\begin{array}{l}\text { Tachybaptus } \\
\text { ruficollis }\end{array}$ & Mali gnjurac & $\mathrm{PM}, \mathrm{WV}$ & 2 & $(1-22)$ & Lc & & \\
\hline 34. & Podiceps cristatus & Ćubasti gnjurac & $\mathrm{PM}, \mathrm{WV}$ & 2 & $(1-22)$ & Lc & & \\
\hline 35. & P. griesegena & Riđogrli gnjurac & $\mathrm{PM}, \mathrm{WV}$ & 2 & $(1-12)$ & & EN & \\
\hline 36. & P. auritus & Ušati gnjurac & $\mathrm{PM}, \mathrm{WV}$ & 2 & $(1-3)$ & & & \\
\hline 37. & P. nigricollis & Crnogrli gnjurac & $\mathrm{PM}, \mathrm{WV}$ & 2 & $(1-25)$ & & EN & \\
\hline 38. & Puffinus yelkouan & Jadranski zovoj & PM & 2 & $3-650$ & & VU & \\
\hline 39. & $\begin{array}{l}\text { Phalacrocorax } \\
\text { carbo }\end{array}$ & Veliki vranac & $\mathrm{PM}, \mathrm{WV}$ & 1,2 & $(1-20)$ & & $\mathrm{Nt}$ & \\
\hline 40. & P. aristotelis & Morski vranac & $\mathrm{Sv}$ & 1,2 & $(1-16)$ & Lc & & \\
\hline 41. & $\begin{array}{l}\text { Microcarbo } \\
\text { pygmaeus }\end{array}$ & Mali vranac & $\mathrm{PM}, \mathrm{WV}$ & 1 & $(1-3)$ & Lc & CR & \\
\hline 42. & Ciconia nigra & Crna roda & $\mathrm{RV}$ & 3,6 & (1) & & VU & \\
\hline 43. & C. ciconia & Bijela roda & $\mathrm{RV}$ & 9 & (2) & & $\mathrm{Nt}$ & \\
\hline 44. & Botaurus stellaris & Bukavac & $\mathrm{RV}$ & 1,10 & $(1)$ & & EN & \\
\hline 45. & $\begin{array}{l}\text { Ixobrychus } \\
\text { minutus }\end{array}$ & Čapljica voljak & SV,PM & 2 & (1) & & Lc & \\
\hline 46. & $\begin{array}{l}\text { Nycticorax } \\
\text { nycticorax }\end{array}$ & Gak & PM & 1 & $(1-20)$ & & $\mathrm{Nt}$ & \\
\hline 47. & Ardeola ralloides & Žuta čaplja & PM & 1 & $(1-8)$ & & EN & \\
\hline 48. & Egretta garzetta & $\begin{array}{l}\text { Mala bijela } \\
\text { čaplja }\end{array}$ & PM, WV 0 & 1 & $(1-22)$ & & VU & \\
\hline 49. & Ardea alba & $\begin{array}{l}\text { Velika bijela } \\
\text { čaplja }\end{array}$ & PM,WV & 1 & $(1-13)$ & & EN & \\
\hline 50. & A. purpurea & Čaplja danguba & PM & 1 & $(1-12)$ & & EN & \\
\hline 51. & A. cinerea & Siva čaplja & $\mathrm{PM}, \mathrm{WV}$ & 1 & $(1-7)$ & Lc & Lc & Lc \\
\hline 52. & $\begin{array}{l}\text { Platalea } \\
\text { leucoropdia }\end{array}$ & Žličarka & PM & 1 & $1-2$ & EN & & \\
\hline 53. & Pernis apivorus & Škanjac osaš & SV,PM C14 & 7 & $\begin{array}{l}30-50 \\
(2-30)\end{array}$ & & Nt & \\
\hline 54. & Milvus migrans & Crna lunja & RV & 3 & $(1)$ & & EN & \\
\hline
\end{tabular}




\begin{tabular}{|c|c|c|c|c|c|c|c|c|}
\hline 55. & $\begin{array}{l}\text { Neophron } \\
\text { percnopterus }\end{array}$ & Crkavica & RV & 6 & $1-2$ & & $\mathrm{RE}$ & \\
\hline 56. & Gyps fulvus & Bjeloglavi sup & RV & 6 & $3-10$ & & $\mathrm{RE}$ & \\
\hline 57. & $\begin{array}{l}\text { Aegypius } \\
\text { monachus }\end{array}$ & Crni lešinar & RV & 6 & 1 & & $\mathrm{RE}$ & \\
\hline 58. & $\begin{array}{l}\text { Circaetus } \\
\text { gallicus }\end{array}$ & Zmijar & SV,PM, C15 & 6 & $25-30$ & & EN & \\
\hline 59. & $\begin{array}{l}\text { Circus } \\
\text { aeruginosus }\end{array}$ & Eja močvarica & PM & $2,3,6,9$ & $1-20$ & & EN & \\
\hline 60. & C. cyaneus & Eja strnjarica & PM, WV & $2,3,6$ & $(1-5)$ & Lc & & \\
\hline 61. & C. pygargus & Eja livadarka & $\begin{array}{l}\text { SV, WV, } \\
\text { C14 }\end{array}$ & $3,6,9$ & $5-10(1-3)$ & & EN & \\
\hline 62. & Accipiter gentilis & Jastreb & R, C14 & 7,8 & $120-150$ & & Lc & \\
\hline 63. & A. nisus & Kobac & R, C15 & 7,8 & $350-400$ & & Lc & \\
\hline 64. & A. brevipes & $\begin{array}{l}\text { Kratkoprsti } \\
\text { kobac }\end{array}$ & PM & 3 & (1) & & $\mathrm{CR}$ & \\
\hline 65. & Buteo buteo & Škanjac & R, C14 & $3,5,6,9$ & $250-300$ & & Lc & \\
\hline 66. & B. rufinus & Riđi škanjac & PM & 5,9 & 1 & & CR & \\
\hline 67. & Aquila pomarina & Orao kliktaš & PM & 6 & (1) & & EN & \\
\hline 68. & A. chrysaetos & Suri orao & R, C14 & 6,9 & 3-5 & & CR & \\
\hline 69. & A. fasciata & Prugasti orao & SV, PM & 6 & $1-2$ & & CR & \\
\hline 70. & Pandion haliaetus & Bukoč & PM & 1,2 & $(1)$ & & $\mathrm{RE}$ & \\
\hline 71. & Falco naumanni & $\begin{array}{l}\text { Bjelonokta } \\
\text { vjetruša }\end{array}$ & PM & 6 & $(1-18)$ & & CR & \\
\hline 72. & F. tinnunculus & Vjetruša & $\begin{array}{l}\text { SV, WV, } \\
\text { C13 }\end{array}$ & 6,9 & $500-700$ & & Lc & \\
\hline 73. & F. vespertinus & $\begin{array}{l}\text { Crvenonoga } \\
\text { vjetruša }\end{array}$ & PM & 5 & $(1-27)$ & DD & & \\
\hline 74. & F. columbarius & Mali sokol & RV & 3 & $(1)$ & & & EN \\
\hline 75. & F. subbuteo & $\begin{array}{l}\text { Sokol } \\
\text { lastavičar }\end{array}$ & SV, PM, B3 & 7,9 & $30-50$ & & Nt & \\
\hline 76. & F. eleonorae & Eleonorin sokol & RV & 4,6 & $(1)$ & & EN & \\
\hline 77. & F. biarmicus & Krški sokol & $\mathrm{RV}$ & 3 & (1) & & $\mathrm{CR}$ & \\
\hline 78. & F. cherrug & Stepski sokol & RV & 2,6 & $(1)$ & & $\mathrm{CR}$ & \\
\hline 79. & F. peregrinus & Sivi sokol & R, C 13 & 3,6 & $10-12$ & & EN & \\
\hline 80. & Rallus aquaticus & Kokošica & PM, WV & 2 & $(1)$ & & Lc & \\
\hline 81. & Porzana porzana & Riđa štijoka & PM, WV & 2 & $(1)$ & & EN & \\
\hline 82. & Porzana parva & Siva štijoka & RV & 3 & $(1)$ & & EN & \\
\hline 83. & Porzana pusilla & Mala štijoka & RV & 3 & $(1)$ & & CR & \\
\hline 84. & Crex crex & Kosac & PM & 10 & $(1-2)$ & & VU & \\
\hline
\end{tabular}




\begin{tabular}{|c|c|c|c|c|c|c|c|c|}
\hline 85. & $\begin{array}{l}\text { Galinulla } \\
\text { chloropus }\end{array}$ & Mlakuša & RV & 12 & (1) & & Lc & \\
\hline 86. & Fulica atra & Liska & WV, PM & 1,2 & $(1-400)$ & & Lc & \\
\hline 87. & Grus grus & Ždral & PM & $1-6$ & $(1-150)$ & $\mathrm{Nt}$ & & \\
\hline 88. & $\begin{array}{l}\text { Haematopus } \\
\text { ostralegus }\end{array}$ & Oštrigar & PM & 1,2 & $(1-11)$ & $\mathrm{Lc}$ & & \\
\hline 89. & $\begin{array}{l}\text { Himantopus } \\
\text { himantopus }\end{array}$ & Vlastelica & PM & 1,2 & $(1-3)$ & & EN & \\
\hline 90. & $\begin{array}{l}\text { Charadrius } \\
\text { dubius }\end{array}$ & Kulik sljepčić & $\begin{array}{l}\text { SV, PM, } \\
\text { C } 13 \\
\end{array}$ & 1,2 & $10-15$ & & $\mathrm{Nt}$ & \\
\hline 91. & C. hiaticula & Kulik blatarić & RV & 1,2 & (1) & NT & & \\
\hline 92. & C. alexandrinus & Morski kulik & RV & 1,2 & $(1-17)$ & & CR & \\
\hline 93. & C. morinellus & Šareni kulik & PM & 9,10 & $(1-2)$ & & & \\
\hline 94. & Vanellus vanellus & Vivak & RV & 2 & $(1-3)$ & & Lc & \\
\hline 95. & Calidris alba & Bijeli žalar & RV & 2 & (1) & & & \\
\hline 96. & C. minuta & Mali žalar & PM & 2 & $(1-7)$ & $\mathrm{LC}$ & & \\
\hline 97. & C. temminckii & Sijedi žalar & RV & 2 & (1) & $\mathrm{LC}$ & & \\
\hline 98. & C. alpina & Žalar cirikavac & PM, WV & 2 & $(1-15)$ & & & $\mathrm{Nt}$ \\
\hline 99. & $\begin{array}{l}\text { Gallinago } \\
\text { gallinago }\end{array}$ & Šljuka kozica & PM & 9,14 & $(1-3)$ & & CR & \\
\hline 100. & $\begin{array}{l}\text { Scolopax } \\
\text { rusticola }\end{array}$ & Šljuka & PM, WV & $3,5,7,8$ & $(1-3)$ & & $\mathrm{CR}$ & \\
\hline 101. & $\begin{array}{l}\text { Numenius } \\
\text { arquata }\end{array}$ & Veliki potviždač & PM, WV & 1 & (1) & $\mathrm{Lc}$ & & \\
\hline 102. & Tringa erythropus & Crna prutka & RV & 2 & $(1-2)$ & $\mathrm{Lc}$ & & \\
\hline 103. & T. totanus & $\begin{array}{l}\text { Crvenonoga } \\
\text { prutka }\end{array}$ & PM, WV & 2 & $(1-3)$ & & $\mathrm{CR}$ & \\
\hline 104. & T. nebularia & $\begin{array}{l}\text { Krivokljuna } \\
\text { prutka }\end{array}$ & PM & 2 & (1) & $\mathrm{Lc}$ & & \\
\hline 105. & T. ochropus & Crnokrila prutka & RV & 2 & $(1-2)$ & Lc & & \\
\hline 106. & T. glareola & Prutka migavica & PM & $1-3$ & $(1-2)$ & Lc & & \\
\hline 107. & Actitis hypoleucos & Mala prutka & PM & 2 & $(1-13)$ & & $\mathrm{VU}$ & \\
\hline 108. & $\begin{array}{l}\text { Ichthyaetus } \\
\text { melanocephalus }\end{array}$ & Crnoglavi galeb & RV & 1,2 & $(1-2)$ & & & \\
\hline 109. & $\begin{array}{l}\text { Hydrocoloeus } \\
\text { minutus }\end{array}$ & Mali galeb & RV & 1,2 & $(1-20)$ & & & \\
\hline 110. & $\begin{array}{l}\text { Chroicocephalus } \\
\text { ridibundus }\end{array}$ & Riječni galeb & PM, WV & 1,2 & $(1-600)$ & & $\mathrm{Nt}$ & \\
\hline 111. & Larus canus & Olujni galeb & WV & 1,2 & $(1-30)$ & $\mathrm{Lc}$ & & Lc \\
\hline 112. & L. fuscus & Mrki galeb & RV & 1,2 & $(1-2)$ & & & \\
\hline 113. & L. michahellis & Galeb klaukavac & $\mathrm{R}$ & $1-9$ & $\begin{array}{l}1-950 \\
(20-300)\end{array}$ & & $\mathrm{Lc}$ & \\
\hline
\end{tabular}




\begin{tabular}{|c|c|c|c|c|c|c|c|}
\hline 114. & Sterna caspia & Velika čigra & RV & 1 & (1) & & \\
\hline 115. & S. hirundo & Obična čigra & SV C 15 & 1,2 & $2-4(1-12)$ & $\mathrm{Nt}$ & \\
\hline 116. & $\begin{array}{l}\text { Thalasseus } \\
\text { sandvicensis }\end{array}$ & $\begin{array}{l}\text { Dugokljuna } \\
\text { čigra }\end{array}$ & PM, WV & 1,2 & $(1-10)$ & & $\mathrm{Nt}$ \\
\hline 117. & $\begin{array}{l}\text { Chlidonias } \\
\text { hybridus }\end{array}$ & Bjelobrada čigra & PM & 1 & (1) & $\mathrm{Nt}$ & \\
\hline 118. & C. niger & Crna čigra & PM & 1 & $(1-3)$ & $\mathrm{RE}$ & \\
\hline 119. & C. leucopterus & Bjelokrila čigra & PM & 1 & $(1-3)$ & $\mathrm{RE}$ & \\
\hline 120. & Columba livia & Divlji golub & SV, C15 & 6 & $1000-1500$ & Lc & \\
\hline 120a & $\begin{array}{l}\text { C. livia f. } \\
\text { domestica }\end{array}$ & Pitomi golub & R, C13 & 12 & $1500-2000$ & Lc & \\
\hline 121. & C. oenas & Golub dupljaš & PM, WV & 3,6 & $1-18$ & EN & \\
\hline 122. & C. palumbus & Golub grivnjaš & $\begin{array}{l}\text { SV, PM, } \\
\text { WV C14 }\end{array}$ & 6,7 & $2(3-180)$ & Lc & \\
\hline 123. & $\begin{array}{l}\text { Streptopelia } \\
\text { decaocto }\end{array}$ & Gugutka & R, C15 & 12 & $3700-4000$ & Lc & \\
\hline 124. & S. turtur & Grlica & SV, C 15 & $3,4,5$ & $1200-1500$ & Lc & \\
\hline 125. & Cuculus canorus & Kukavica & SV, C15 & $3,4,5$ & $400-650$ & Lc & \\
\hline 126. & Tyto alba & Kukuvija & PM, WV & 3,11 & (1) & $\mathrm{Nt}$ & \\
\hline 127. & Otus scops & Ćuk & $\begin{array}{l}\text { SV,PM, C } \\
15\end{array}$ & $3,4,5,11$ & $1800-2000$ & Lc & \\
\hline 128. & Bubo bubo & Ušara & R, C 15 & $4,5,6$ & $250-320$ & $\mathrm{Nt}$ & \\
\hline 129. & $\begin{array}{l}\text { Glaucidium } \\
\text { passerinum }\end{array}$ & Mali ćuk & $\mathbf{R}$ & $7,7 a$ & $25-50$ & VU & \\
\hline 130. & Athene noctua & Sivi ćuk & R, C 14 & $3,4,5,6$ & $400-420$ & Nt & \\
\hline 131. & Strix aluco & Šumska sova & R, C 15 & $3,7,11$ & $1100-1200$ & Lc & \\
\hline 132. & S. uralensis & Planinska sova & R, C 15 & 7,7a, 8 & $150-180$ & Nt & \\
\hline 133. & Asio otus & Mala ušara & RV & 6 & (1) & Lc & \\
\hline 134. & $\begin{array}{l}\text { Aegolius } \\
\text { funereus }\end{array}$ & Planinski ćuk & R, C 15 & $7 a$ & $150-200$ & $\mathrm{Nt}$ & \\
\hline 135. & $\begin{array}{l}\text { Caprimulgus } \\
\text { eurpaeus }\end{array}$ & Leganj & PM, SV, B 3 & 3,5 & $80-120$ & Lc & \\
\hline 136. & Apus apus & Čiopa & $\begin{array}{l}\text { SV,PM, C } \\
13\end{array}$ & 3,6 & $600-800$ & Lc & \\
\hline 137. & Apus pallidus & Smeđa čiopa & $\begin{array}{l}\text { SV,PM, C } \\
13 \\
\end{array}$ & 6,12 & $150-200$ & Lc & \\
\hline 138. & $\begin{array}{l}\text { Tachymarptis } \\
\text { melba }\end{array}$ & Bijela čiopa & $\begin{array}{l}\text { SV,PM, C } \\
15\end{array}$ & 6 & $500-600$ & Lc & \\
\hline 139. & Coracias garrulus & Zlatovrana & PM & 3 & $(1-2)$ & CR & \\
\hline 140. & Alcedo atthis & Vodomar & PM, WV & 2 & $\begin{array}{l}15-20 \\
(1-5) \\
\end{array}$ & $\mathrm{Nt}$ & \\
\hline
\end{tabular}




\begin{tabular}{|c|c|c|c|c|c|c|c|}
\hline 141. & Merops apiaster & Pčelarica & SV,PM C 13 & $3,4,5$ & $\begin{array}{l}50-60 \\
(1-55)\end{array}$ & Lc & \\
\hline 142. & Upupa epops & Pupavac & $\begin{array}{l}\text { SV,PM, C } \\
13\end{array}$ & $3,4,11$ & $570-600$ & Lc & \\
\hline 143. & Jynx torquilla & Vijoglav & $\begin{array}{l}\text { SV,PM, C } \\
13\end{array}$ & $3,4,11$ & $1400-1600$ & Lc & \\
\hline 144. & Picus canus & Siva žuna & r, C 13 & 7,8 & $250-300$ & Lc & \\
\hline 145. & P. viridis & Zelena žuna & r, B3 & 3,11 & $(1-3)$ & $\mathrm{Nt}$ & \\
\hline 146. & $\begin{array}{l}\text { Dryocopus } \\
\text { martius }\end{array}$ & Crna žuna & r, C13 & 7,8 & $150-200$ & Lc & \\
\hline 147. & $\begin{array}{l}\text { Dendrocopos } \\
\text { major }\end{array}$ & Veliki djetlić & r, C 13 & $3,7,11$ & $450-500$ & Lc & \\
\hline 148. & D. syriacus & Sirijski djetlić & RV & 12 & (1) & $\mathrm{Nt}$ & \\
\hline 149. & D. medius & $\begin{array}{l}\text { Crvenoglavi } \\
\text { djetlić }\end{array}$ & R, C 13 & 5,6 & $250-300$ & Lc & \\
\hline 150. & D. leucotos & $\begin{array}{l}\text { Planinski } \\
\text { djetlić }\end{array}$ & R, C 15 & 7,8 & $220-280$ & $\mathrm{Nt}$ & \\
\hline 151. & D. minor & Mali djetlić & r, C 15 & 7,8 & $350-400$ & Lc & \\
\hline 152. & \begin{tabular}{|l}
$\begin{array}{l}\text { Picodes } \\
\text { tridactylus }\end{array}$ \\
\end{tabular} & Troprsti djetlić & R, C 15 & 8 & $35-40$ & $\mathrm{Nt}$ & \\
\hline 153. & Lanius collurio & Rusi svračak & $\begin{array}{l}\text { SV,PM, C } \\
15\end{array}$ & $3-7,10$ & $\begin{array}{l}8.800- \\
10.100\end{array}$ & Lc & \\
\hline 154. & L. minor & Sivi svračak & PM, SV, A2 & 3,5 & $35-40$ & Lc & \\
\hline 155. & L. excubitor & Veliki svračak & PM, WV & 3,5 & $(3-10)$ & & $\mathrm{Nt}$ \\
\hline 156. & L. senator & $\begin{array}{l}\text { Riđoglavi } \\
\text { svračak }\end{array}$ & $\begin{array}{l}\text { SV, PM, } \\
\text { C } 15 \\
\end{array}$ & $3,4,5$ & $160-220$ & Lc & \\
\hline 157. & Oriolus oriolus & Vuga & $\begin{array}{l}\text { SV, PM, } \\
\text { C } 15\end{array}$ & $3,4,5,6,7$ & $\begin{array}{l}4.700- \\
5.300\end{array}$ & Lc & \\
\hline 158. & $\begin{array}{l}\text { Garrulus } \\
\text { glandarius }\end{array}$ & Šojka & R, C 15 & $3-8$ & $1400-1500$ & Lc & \\
\hline 159. & Pica pica & Svraka & R, C 15 & $5,12,14,15$ & $150-200$ & Lc & \\
\hline 160. & $\begin{array}{l}\text { Nucifraga } \\
\text { caryocatactes }\end{array}$ & Kreja & WV, PM & 3,8 & $220-250$ & Lc & \\
\hline 161. & $\begin{array}{l}\text { Pyrrhocorax } \\
\text { graculus }\end{array}$ & $\begin{array}{l}\text { Žutokljuna } \\
\text { galica }\end{array}$ & R, C 13 & 6,9 & $\begin{array}{l}400-650 \\
(1-400) \\
\end{array}$ & Lc & \\
\hline 162. & Corvus monedula & Čavka & RV & 3 & $150-180$ & Lc & \\
\hline 163. & C. corone cornix & Siva vrana & R, C 15 & $3,5,11$ & $250-300$ & Lc & \\
\hline 164. & C. corax & Gavran & R, C 15 & $3-11$ & 70-100 & Lc & \\
\hline 165. & \begin{tabular}{|l|} 
Calandrella \\
brachydacytla
\end{tabular} & $\begin{array}{l}\text { Kratkoprsta } \\
\text { ševa }\end{array}$ & SV & 3,9 & $1-3$ & $\mathrm{Nt}$ & \\
\hline 166. & Galerida cristata & Kukmasta ševa & $\begin{array}{l}\text { SV,PM, WV, } \\
\text { C } 15\end{array}$ & 3,11 & $1200-1500$ & Lc & \\
\hline
\end{tabular}




\begin{tabular}{|c|c|c|c|c|c|c|c|}
\hline 167. & Lullula arborea & Ševa krunica & $\begin{array}{l}\text { SV,PM, WV, } \\
\text { C } 15\end{array}$ & $3,9,11$ & $\begin{array}{l}900-1000 \\
(1-250)\end{array}$ & Lc & \\
\hline 168. & Alauda arvensis & Poljska ševa & $\begin{array}{l}\text { SV,PM, WV, } \\
\text { C } 15\end{array}$ & $3,9,11$ & $\begin{array}{l}1000-1200 \\
(1-400)\end{array}$ & Lc & \\
\hline 169. & $\begin{array}{l}\text { Eremophila } \\
\text { alpestris }\end{array}$ & Planinska ševa & RV & 9 & (1) & EN & \\
\hline 170. & Riparia riparia & Bregunica & PM & 2,3 & $(1-50)$ & VU & \\
\hline 171. & $\begin{array}{l}\text { Ptyonoprogne } \\
\text { rupestris }\end{array}$ & $\begin{array}{l}\text { Hridna } \\
\text { lastavica }\end{array}$ & $\begin{array}{l}\text { SV, PM, } \\
\text { C } 15\end{array}$ & 6 & $\begin{array}{l}450-500 \\
(200-250)\end{array}$ & Lc & \\
\hline 172. & Hirundo rustica & Lastavica & $\begin{array}{l}\text { SV, PM, } \\
\text { C } 15\end{array}$ & 12 & $\begin{array}{l}6200-7100 \\
(2500- \\
3000)\end{array}$ & Lc & \\
\hline 173. & Cecropis daurica & $\begin{array}{l}\text { Pećinska } \\
\text { lastavica }\end{array}$ & $\begin{array}{l}\text { SV, PM, } \\
\text { C } 15\end{array}$ & 6,12 & $\begin{array}{l}50-70(40- \\
50)\end{array}$ & $\mathrm{Nt}$ & \\
\hline 174. & $\begin{array}{l}\text { Delichon } \\
\text { urbicum }\end{array}$ & Piljak & $\begin{array}{l}\text { SV, PM, } \\
\text { C } 15\end{array}$ & 6,12 & $\begin{array}{l}3800-4400 \\
(3000- \\
3500)\end{array}$ & Lc & \\
\hline 175. & $\begin{array}{l}\text { Panurus } \\
\text { biarmicus }\end{array}$ & Brkata sjenica & RV & 5 & (10) & EN & \\
\hline 176. & Poecile palustris & $\begin{array}{l}\text { Crnoglava } \\
\text { sjenica }\end{array}$ & R, WV, C 15 & $4,5,7$ & $\begin{array}{l}5500-6000 \\
(2000- \\
3000)\end{array}$ & Lc & \\
\hline 177. & P. lugubris & Mrka sjenica & R, C 13 & 4,5 & $250-380$ & Lc & \\
\hline 178. & P. montanus & $\begin{array}{l}\text { Planinska } \\
\text { sjenica }\end{array}$ & R, C 13 & 7,10 & $300-500$ & Lc & \\
\hline 179. & $\begin{array}{l}\text { Lophophanes } \\
\text { cristatus }\end{array}$ & $\begin{array}{l}\text { Kukmasta } \\
\text { sjenica }\end{array}$ & R, C 15 & 8 & $900-1000$ & Lc & \\
\hline 180. & Periparus ater & Jelova sjenica & R, C 15 & 8,11 & $2500-3000$ & Lc & \\
\hline 181. & $\begin{array}{l}\text { Cyanistes } \\
\text { caeruleus }\end{array}$ & $\begin{array}{l}\text { Plavetna } \\
\text { sjenica }\end{array}$ & R, C 15 & 4,5 & $\begin{array}{l}5100- \\
6.300\end{array}$ & Lc & \\
\hline 182. & C. cyanus & Bijela sjenica & $\mathrm{RV}$ & 5 & (1) & & \\
\hline 183. & Parus major & Velika sjenica & R, C 15 & $3-11$ & $\begin{array}{l}13.800- \\
16.300\end{array}$ & Lc & \\
\hline 184. & Remiz pendulinus & $\begin{array}{l}\text { Sjenica } \\
\text { mošnjarka }\end{array}$ & PM & 3 & (1) & Lc & \\
\hline 185. & $\begin{array}{l}\text { Aegithalos } \\
\text { caudatus }\end{array}$ & $\begin{array}{l}\text { Dugorepa } \\
\text { sjenica }\end{array}$ & $\begin{array}{l}\text { SV,PM,WV, } \\
\text { C13 }\end{array}$ & $4,5,7$ & $\begin{array}{l}880-1000 \\
(1-100) \\
\end{array}$ & Lc & \\
\hline 186. & Sitta europaea & Brgljez & R, C15 & 5,7 & $\begin{array}{l}6300-7500 \\
(1-1000)\end{array}$ & Lc & \\
\hline 187. & S. neumayer & $\begin{array}{l}\text { Brgljez } \\
\text { kamenjar }\end{array}$ & R, C15 & 6 & $\begin{array}{l}650-800 \\
(1-400)\end{array}$ & Lc & \\
\hline 188. & $\begin{array}{l}\text { Tichodroma } \\
\text { muraria }\end{array}$ & $\begin{array}{l}\text { Crvenokrili } \\
\text { zidarčac }\end{array}$ & WV,PM & 6 & $(15-20)$ & & $\mathrm{Nt}$ \\
\hline
\end{tabular}




\begin{tabular}{|c|c|c|c|c|c|c|}
\hline 189. & Certhia familiaris & \begin{tabular}{|l} 
Kratkokljuni \\
puzavac
\end{tabular} & R, C13 & 7 & $\begin{array}{l}80-120 \\
(1-30) \\
\end{array}$ & Lc \\
\hline 190. & C. brachydacytla & \begin{tabular}{|l} 
Dugokljuni \\
puzavac
\end{tabular} & R, C15 & 8 & $\begin{array}{l}480-500 \\
(200-300)\end{array}$ & Lc \\
\hline 191. & $\begin{array}{l}\text { Troglodytes } \\
\text { troglodytes }\end{array}$ & Palčić & $\begin{array}{l}\text { SV,PM,WV, } \\
\text { C12 }\end{array}$ & $3-7$ & $\begin{array}{l}800-1000 \\
(2500- \\
3000)\end{array}$ & Lc \\
\hline 192. & Cinclus cinclus & Vodenkos & R, C12 & 12 & $\begin{array}{l}10-20(25- \\
30)\end{array}$ & Lc \\
\hline 193. & Regulus regulus & $\begin{array}{l}\text { Zlatoglavi } \\
\text { kraljić }\end{array}$ & PM, WV & $3,8,11$ & $\begin{array}{l}(1500- \\
2000)\end{array}$ & Lc \\
\hline 194. & R. ignicapilla & $\begin{array}{l}\text { Vatroglavi } \\
\text { kraljić }\end{array}$ & PM, WV & 3,4 & $\begin{array}{l}(1000- \\
1200)\end{array}$ & Lc \\
\hline 195. & $\begin{array}{l}\text { Phylloscopus } \\
\text { bonelli }\end{array}$ & Gorski zviždak & RV & 3 & (1) & CR \\
\hline 196. & P. sibilatrix & Šumski zviždak & SV, PM C13 & 3-11 & $\begin{array}{l}25-60 \\
(500- \\
1500)\end{array}$ & Lc \\
\hline 197. & P. collybita & Zviždak & $\begin{array}{l}\text { SV, PM, } \\
\text { WV, C } 13\end{array}$ & $4-10$ & $\begin{array}{l}28900- \\
31400 \\
(1900- \\
3000)\end{array}$ & Lc \\
\hline 198. & P. trochilus & Brezov zviždak & PM & 3-11 & $(1-30)$ & VU \\
\hline 199. & P. inornatus & Azijski zviždak & RV & $3 a$ & (1) & \\
\hline 200. & Iduna pallida & Sivi voljić & SV, B9 & 3,5 & $15-20$ & Lc \\
\hline 201. & \begin{tabular}{|l|} 
Hippolais \\
olivetorum
\end{tabular} & Voljić maslinar & RV & 3 & $5-10$ & $\mathrm{Nt}$ \\
\hline 202. & H. icterina & Žuti voljić & PM & 3,5 & $(150-200)$ & $\mathrm{Nt}$ \\
\hline 203. & H. pollyglotta & \begin{tabular}{|l|} 
Kratkokrili \\
voljić
\end{tabular} & SV, C13 & $3,5,11$ & $40-60$ & Lc \\
\hline 204. & $\begin{array}{l}\text { Acrocephalus } \\
\text { schoenobaenus }\end{array}$ & $\begin{array}{l}\text { Trstenjak } \\
\text { rogožar }\end{array}$ & PM & 3,7 & $(1-5)$ & Lc \\
\hline 205. & A. plaustris & $\begin{array}{l}\text { Trstenjak } \\
\text { mlakar }\end{array}$ & PM & 3 & (1) & Lc \\
\hline 206. & A. scirpaceus & $\begin{array}{l}\text { Trstenjak } \\
\text { cvrkutić }\end{array}$ & PM & 3 & (1) & Lc \\
\hline 207. & A. arundinaceus & Veliki trstenjak & PM & 3 & $(1-5)$ & Lc \\
\hline 208. & Locustella naevia & Trstenjak cvrčić & RV & 3 & (1) & $\mathrm{Nt}$ \\
\hline 209. & Cisticola juncidis & $\begin{array}{l}\text { Šivalica } \\
\text { muharka }\end{array}$ & SV, B3 & 3 & $1-2$ & Lc \\
\hline 210. & Sylvia cantillans & \begin{tabular}{|l} 
Bjelobrka \\
grmuša
\end{tabular} & $\begin{array}{l}\text { SV, PM, } \\
\text { C15 }\end{array}$ & $3,4,5$ & $\begin{array}{l}15100- \\
18900 \\
\end{array}$ & Lc \\
\hline
\end{tabular}




\begin{tabular}{|c|c|c|c|c|c|c|}
\hline 211. & S. melanocephala & $\begin{array}{l}\text { Crnoglava } \\
\text { grmuša }\end{array}$ & R, C13 & $3,4,5$ & $1000-1100$ & Lc \\
\hline 212. & S. hortensis & Velika grmuša & $\begin{array}{l}\text { SV, PM, } \\
\text { C15 }\end{array}$ & $3,4,5$ & $6200-6900$ & Lc \\
\hline 213. & S. nisoria & $\begin{array}{l}\text { Pjegava } \\
\text { grmuša }\end{array}$ & SV, PM, B9 & 5,9 & $120-150$ & Lc \\
\hline 214. & S. curruca & $\begin{array}{l}\text { Grmuša } \\
\text { čevrljinka }\end{array}$ & $\begin{array}{l}\text { SV, PM, } \\
\text { C15 }\end{array}$ & 8,911 & $4300-5000$ & Lc \\
\hline 215. & S. communis & $\begin{array}{l}\text { Grmuša } \\
\text { pjenica }\end{array}$ & $\begin{array}{l}\text { SV, PM, } \\
\text { C13 }\end{array}$ & $3,4,10,11$ & $\begin{array}{l}750-880 \\
(500- \\
1000)\end{array}$ & Lc \\
\hline 216. & S. borin & Siva grmuša & PM & $4-12$ & $1-300$ & Lc \\
\hline 217. & S. atricapilla & $\begin{array}{l}\text { Crnokapa } \\
\text { grmuša }\end{array}$ & $\begin{array}{l}\text { SV, PM, } \\
\text { WV, C15 }\end{array}$ & $3-15$ & $\begin{array}{l}41.600- \\
44.100\end{array}$ & Lc \\
\hline 218. & Muscicapa striata & Muharica & $\begin{array}{l}\text { SV, PM, } \\
\text { C15 }\end{array}$ & $3,4-7$ & $750-900$ & Lc \\
\hline 219. & $\begin{array}{l}\text { Erithacus } \\
\text { rubecula }\end{array}$ & Crvendać & $\begin{array}{l}\text { SV, PM, } \\
\text { WV, C15 }\end{array}$ & $3-15$ & $\begin{array}{l}14.000- \\
15.000 \\
(10.000- \\
20.000)\end{array}$ & Lc \\
\hline 220. & $\begin{array}{l}\text { Luscinia } \\
\text { megarhynchos }\end{array}$ & Slavuj & $\begin{array}{l}\text { SV, PM, } \\
\text { C15 }\end{array}$ & $3-15$ & $\begin{array}{l}12.000- \\
13.000 \\
(15.000- \\
20.000)\end{array}$ & Lc \\
\hline 221. & Ficedula parva & Mala muharica & PM & 7 & (1) & $\mathrm{Nt}$ \\
\hline 222. & F. albicollis & $\begin{array}{l}\text { Bjelovrata } \\
\text { muharica }\end{array}$ & PM & $3-15$ & (1) & Lc \\
\hline 223. & F. hypoleuca & $\begin{array}{l}\text { Crnovrata } \\
\text { muharica }\end{array}$ & PM & $3-15$ & $(1-10)$ & Lc \\
\hline 224. & $\begin{array}{l}\text { Phoenicurus } \\
\text { ochruros }\end{array}$ & $\begin{array}{l}\text { Mrka } \\
\text { crvenrepka }\end{array}$ & $\begin{array}{l}\text { SV, PM, } \\
\text { WV, C15 }\end{array}$ & $3-15$ & $\begin{array}{l}1000-1200 \\
(300-500)\end{array}$ & Lc \\
\hline 225. & P. phoenicurus & $\begin{array}{l}\text { Šumska } \\
\text { crvenrepka }\end{array}$ & PM & $3,7,8,9,11$ & $(25-30)$ & Lc \\
\hline 226. & Monticola sxatilis & Kamenjar & $\begin{array}{l}\text { SV, PM, } \\
\text { C14 }\end{array}$ & 4,6 & $440-630$ & $\mathrm{Nt}$ \\
\hline 227. & M. solitarius & Modrokos & SV, PM & 6 & $1200-1900$ & Lc \\
\hline 228. & Saxicola rubetra & $\begin{array}{l}\text { Smeđeglava } \\
\text { travarka }\end{array}$ & SV, PM & $\begin{array}{l}3,4,9 \\
10,11 \\
\end{array}$ & $\begin{array}{l}1(250- \\
500)\end{array}$ & Lc \\
\hline 229. & S. rubicola & $\begin{array}{l}\text { Crnoglava } \\
\text { travarka }\end{array}$ & SV,PM,WV & $3,9,10$ & $1(1-20)$ & Lc \\
\hline 230. & $\begin{array}{l}\text { Oenanthe } \\
\text { oenanthe }\end{array}$ & $\begin{array}{l}\text { Sivkasta } \\
\text { bjeloguza }\end{array}$ & $\begin{array}{l}\text { SV, PM, } \\
\text { C } 15\end{array}$ & 9,10 & $\begin{array}{l}480-600 \\
(400- \\
1000)\end{array}$ & Lc \\
\hline
\end{tabular}




\begin{tabular}{|c|c|c|c|c|c|c|}
\hline 231. & O. melanoleuca & \begin{tabular}{|l|} 
Primorska \\
bjeloguza
\end{tabular} & $\begin{array}{l}\text { SV, PM, } \\
\text { C } 14 \\
\end{array}$ & 4,6 & $350-400$ & Lc \\
\hline 232. & O. hispanica & $\begin{array}{l}\begin{array}{l}\text { Španjolska } \\
\text { bjeloguza }\end{array} \\
\end{array}$ & PM & 2,4 & $(2-3)$ & \\
\hline 233. & Turdus torquatus & Planinski kos & R, PM C 15 & $9,10,11$ & $250-300$ & Lc \\
\hline 234. & T. merula & Kos & R, WV, C 15 & $3-15$ & $\begin{array}{l}41.500- \\
50.300 \\
(15.000- \\
20.000)\end{array}$ & Lc \\
\hline 235. & T. pilaris & Drozd bravenjak & PM, WV & $3,5,5,9$ & $(1-1500)$ & $\mathrm{Nt}$ \\
\hline 236. & T. philomelos & Drozd cikelj & $\begin{array}{l}\text { SV,PM,WV, } \\
\text { C15 }\end{array}$ & 3-11 & $1500-2000$ & Lc \\
\hline 237. & T. iliacus & Mali drozd & WV & 3 & $(1-2)$ & Lc \\
\hline 238. & T. viscivorus & Drozd imelaš & $\mathbf{R}$ & $3-15$ & $\begin{array}{l}1900-2100 \\
(1500- \\
2000)\end{array}$ & Lc \\
\hline 239. & Sturnus vulgaris & Čvorak & $\begin{array}{l}\text { SV, PM, } \\
\text { C } 15\end{array}$ & $3-5$ & $\begin{array}{l}250-300 \\
(1-15.000)\end{array}$ & Lc \\
\hline 240. & S. roseus & Ružičasti čvorak & Sv & 3 & $(1-100)$ & \\
\hline 241. & $\begin{array}{l}\text { Prunella } \\
\text { modularis }\end{array}$ & Sivi popić & $\begin{array}{l}\text { SV,PM,WV, } \\
\text { C15 }\end{array}$ & 3-15 & $2500-3100$ & Lc \\
\hline 242. & P. collaris & Alpski popić & $\begin{array}{l}\text { SV, PM, } \\
\text { WV }\end{array}$ & 9,10 & $120-150$ & VU \\
\hline 243. & Motacilla flava & Žuta pastirica & PM & $3,9,10$ & $\begin{array}{l}(1500- \\
3000)\end{array}$ & Lc \\
\hline 243. & $\begin{array}{l}\text { M. } f . \\
\text { cinereocapilla }\end{array}$ & $\begin{array}{l}\text { Bjelogrla } \\
\text { pastirica }\end{array}$ & PM & 3 & $(1-5)$ & \\
\hline 243. & M.f.feldegg & $\begin{array}{l}\text { Crnoglava } \\
\text { pastirica }\end{array}$ & PM & 3 & $(1-5)$ & \\
\hline 243. & M.f. flava & Žuta pastirica & PM & 3,9 & $(1-20)$ & \\
\hline 244. & M. cinerea & \begin{tabular}{|l|} 
Gorska \\
pastirica
\end{tabular} & $\begin{array}{l}\text { SV,PM, WV, } \\
\text { C } 15\end{array}$ & 6 & $400-500$ & Lc \\
\hline 245. & M. alba & Bijela pastirica & $\begin{array}{l}\text { SV, PM, } \\
\text { WV, C } 15 \\
\end{array}$ & $2,3,12$ & $800-1200$ & Lc \\
\hline 246. & $\begin{array}{l}\text { Anthus } \\
\text { campestris }\end{array}$ & \begin{tabular}{|l|} 
Primorska \\
trepteljka
\end{tabular} & $\begin{array}{l}\text { SV, PM, } \\
\text { C } 15 \\
\end{array}$ & $3,4,9$ & $1200-1500$ & Lc \\
\hline 247. & A. trivialis & $\begin{array}{l}\text { Prugasta } \\
\text { trepteljka }\end{array}$ & $\begin{array}{l}\text { SV, PM, } \\
\text { C } 15\end{array}$ & $7,8,9$ & $4400-5000$ & Lc \\
\hline 248. & A. pratensis & \begin{tabular}{|l} 
Livadna \\
trepteljka
\end{tabular} & PM, WV & 3 & $\begin{array}{l}(500- \\
1000)\end{array}$ & Lc \\
\hline 249. & A. spinoletta & $\begin{array}{l}\text { Planinska } \\
\text { trepteljka }\end{array}$ & $\begin{array}{l}\text { SV, PM, } \\
\text { WV, C } 15\end{array}$ & 10 & $\begin{array}{l}250-300 \\
(1-200)\end{array}$ & VU \\
\hline
\end{tabular}




\begin{tabular}{|c|c|c|c|c|c|c|}
\hline 250. & A. cervinus & $\begin{array}{l}\text { Rusogrla } \\
\text { trepteljka }\end{array}$ & RV & 9 & $(1)$ & \\
\hline 251. & $\begin{array}{l}\text { Emberiza } \\
\text { citrinella }\end{array}$ & Žuta strnadica & SV, WV & $3,4,5,11$ & $(1-3)$ & Lc \\
\hline 252. & E. cirlus & $\begin{array}{l}\text { Crnogrla } \\
\text { strnadica }\end{array}$ & R, C 15 & $3,4,5,11$ & $500-700$ & Lc \\
\hline 253. & E. cia & $\begin{array}{l}\text { Strnadica } \\
\text { cikavica }\end{array}$ & R, C 13 & $5,6,7,8$ & $600-700$ & Lc \\
\hline 254. & E. hortulana & $\begin{array}{l}\text { Vrtna } \\
\text { strnadica }\end{array}$ & $\begin{array}{l}\text { SV, PM, } \\
\text { C } 13\end{array}$ & $5,6,7,8$ & $450-500$ & Lc \\
\hline 255. & E. schoeniclus & $\begin{array}{l}\text { Močvarna } \\
\text { strnadica }\end{array}$ & PM, WV & 3 & $\begin{array}{l}(500- \\
1000)\end{array}$ & Lc \\
\hline 256. & $\begin{array}{l}\text { E. } \\
\text { melanocephala }\end{array}$ & $\begin{array}{l}\text { Crnoglava } \\
\text { strnadica }\end{array}$ & $\begin{array}{l}\text { SV, PM, } \\
\text { C } 13\end{array}$ & $3,5,11$ & $250-300$ & Lc \\
\hline 257. & E. calandra & $\begin{array}{l}\text { Velika } \\
\text { strnadica }\end{array}$ & R, C 15 & 3,50 & $600-700$ & Lc \\
\hline 258. & Fringilla coelebs & Zeba & R, WV, C15 & 3-15 & $\begin{array}{l}34.000- \\
38.000\end{array}$ & Lc \\
\hline 259. & F. montifringilla & Sjeverna zeba & PM, WV & $3,5,7,8$ & $(1-10.000)$ & Lc \\
\hline 260. & Serinus serinus & Žutarica & $\begin{array}{l}\text { SV, PM, wv, } \\
\text { C15 }\end{array}$ & $3,8,11$ & $1500-2000$ & Lc \\
\hline 261. & Chloris chloris & Zelendur & R, C 15 & $3,8,11$ & $\begin{array}{l}2.500- \\
3.100\end{array}$ & Lc \\
\hline 262. & $\begin{array}{l}\text { Carduelis } \\
\text { carduelis }\end{array}$ & Češljugar & R, C 15 & $3,8,11$ & $\begin{array}{l}3.100- \\
3.800\end{array}$ & Lc \\
\hline 263. & Spinus spinus & Čižak & R,wv, C13 & $3,8,11$ & $\begin{array}{l}350-500 \\
(1.000- \\
2.000)\end{array}$ & Lc \\
\hline 264. & $\begin{array}{l}\text { Acanthis } \\
\text { cannabina }\end{array}$ & Juričica & R, C 15 & $3,4,5,11$ & $\begin{array}{l}8.800- \\
9.400 \\
\end{array}$ & Lc \\
\hline 265. & Loxia curvirostra & Krstokljun & R, C 13 & $7,8,9,10,11$ & $\begin{array}{l}2.300- \\
2.500 \\
\end{array}$ & Lc \\
\hline 266. & $\begin{array}{l}\text { Erythrina } \\
\text { erythrina }\end{array}$ & Rujnica & RV & 3 & $(1)$ & \\
\hline 267. & $\begin{array}{l}\text { Pyrrhula } \\
\text { pyrrhula }\end{array}$ & Zimovka & R, C 13 & $5,7,8,10$ & $380-500$ & Lc \\
\hline 268. & $\begin{array}{l}\text { Coccothraustes } \\
\text { coccothraustes }\end{array}$ & Batokljun & R, C 15 & 3-11 & \begin{tabular}{|l|}
$2.400-$ \\
2.600 \\
$(1-5.000)$
\end{tabular} & Lc \\
\hline 269. & $\begin{array}{l}\text { Passer } \\
\text { domesticus }\end{array}$ & Vrabac & R, C 15 & 3,12 & $\begin{array}{l}10.000- \\
12.000\end{array}$ & Lc \\
\hline 270. & P. hispaniolensis & $\begin{array}{l}\text { Španjolski } \\
\text { vrabac }\end{array}$ & $\begin{array}{l}\text { SV, PM, } \\
\text { C } 15\end{array}$ & 3,12 & $1200-1400$ & Lc \\
\hline 271. & P. montanus & Poljski vrabac & R, C13 & 3,12 & $500-900$ & Lc \\
\hline
\end{tabular}




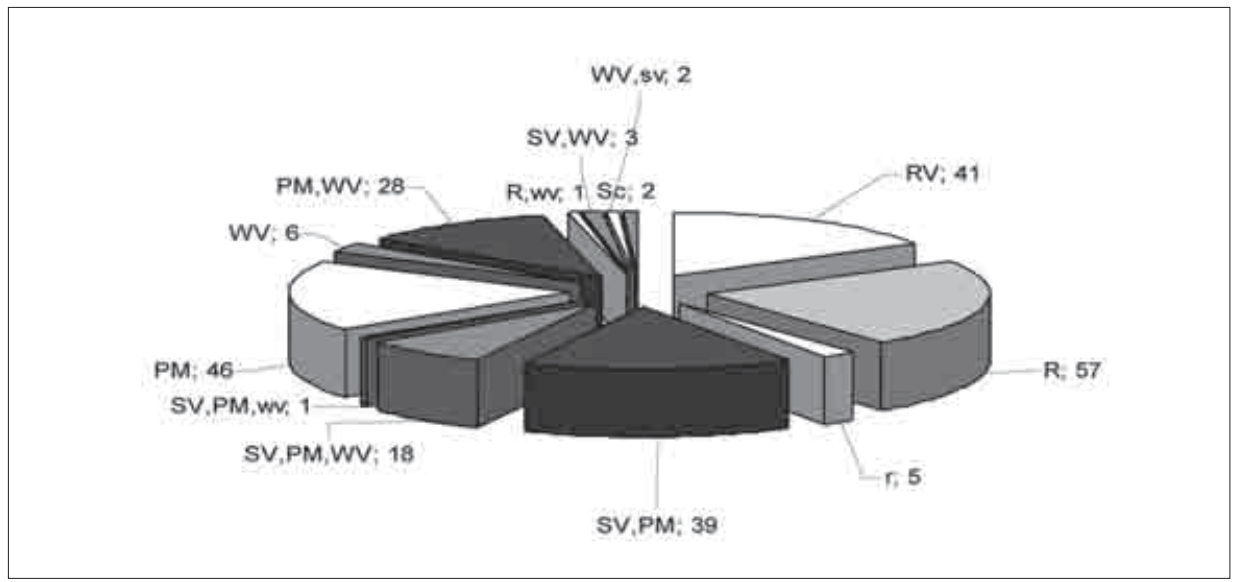

Sl. 2. Sezonski status vrsta, prema Tab. 5.

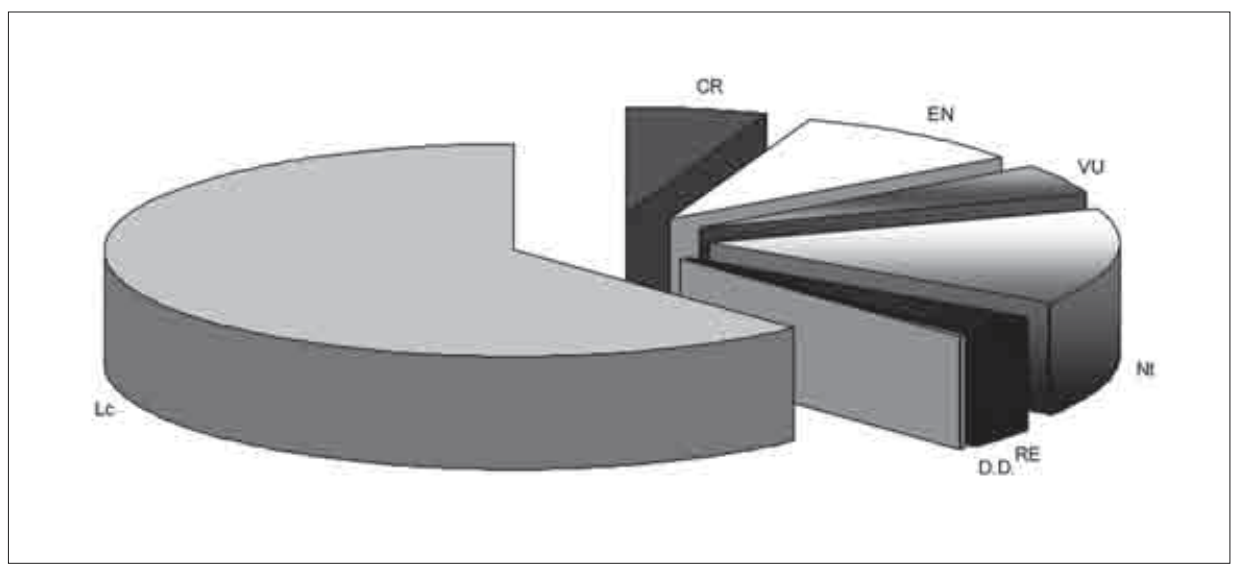

S1. 3. Kategorije ugroženosti velebitskih ptica, prema Tab. 5.

Sezonski status vrsta prikazan je prema Tab. 5., a vidljiv je iz Sl. 2. Većina vrsta ima kombinirani status jer je riječ ili o pticama gnjezdaricama (SV), selicama (PM) ili o stanaricama ( R ), koje pokazuju sklonost vertikalnim migracijama ili manjim selidbama (sv, r). Za 153 vrste se može reći da su za sada na području Velebita svojom brojnošću stabilne, odnosno najmanje zabrinjavajuće (LC), S1. 2.

Za 41 vrstu se može reći da su rijetke, jer su u području istraživanja zabilježene od 1 do 3 puta (S1. 3). 


\section{Rasprava}

Dosadašnjim istraživanjima, sakupljenim literaturnim podatcima o promatranju ptica, podatcima o prepariranim vrstama, a pohranjenim u dvije najveće zbirke ptica u Hrvatskom prirodoslovnom muzeju (HPM) i Zavodu za ornitologiju HAZU u Zagrebu, koje su uhvaćene u različitim dijelovima Velebita, ukupno je zabilježena 271 ptičja vrsta. Od toga je 127 vrsta ptica gnjezdarica. Za 93 vrste se može reći da su razvrstane u jednu od kategorija ugroženosti prema Crvenoj knjizi ugroženih ptica Hrvatske ${ }^{10}$. Osam vrsta su kao gnjezdarice izumrle iz Hrvatske, poput patke lastarke $(A$. acuta), patke žličarke (S. clypeata), a preletnička populacija je stabilna i obje vrste se viđaju u obalnom području južnog Velebita na preletu (u uvali Modrič). Crkavica ( $N$. percnopterus) je izumrla kao gnjezdarica iz cijele Hrvatske i uopće se za sada ne viđa niti na preletu ${ }^{11}$. Bukoč (P. haliaetus) se u Hrvatskoj ne gnijezdi, samo se viđa na preletu u obalnom području, no vrlo rijetko. Isto vrijedi i za supa starješinu (A. monachus) koji je za sada samo jednom zabilježen u NP Paklenica ${ }^{12}$. Bjeloglavi sup ( $G$. fulvus) se trenutno ne gnijezdi u Velebitu, zadnje gniježđenje je zabilježeno 1999. god. ${ }^{13}$ Danas mu je brojnost u kolonijama Kvarnerskih otoka u opadanju (Sušić, usmeno). Na području Velebita se redovito viđa na preletu, prilikom pretraživanja terena u potrazi za hranom. Vrste bjelokrila i crna čigra (C. leucopterus i C. niger) viđaju se na preletu u vrijeme proljetne i jesenske selidbe uz morsku obalu, dok su sredinom 20. st. prestale gnijezditi u Hrvatskoj. Za 22 vrste nije određena kategorija ugoženosti jer se radi o rijetkim i malobrojnim vrstama pa im je nemoguće odrediti precizniji status ugroženosti u Hrvatskoj. U kategoriji kritično ugroženih je 15 vrsta, dok su 23 vrste ugrožene (EN), a 12 je osjetljivih vrsta (VU). U kategoriji vrsta niskog rizika je njih 36, dok je jedna vrsta slabo poznata (DD), crenonoga Danas je brojnost surog orla (Aquila chrysaetos) sve manja i u stalnom opadanju. Procjenjuje se da na cijeloj planini gnijezdi od 3 do 5 parova. Isto se može reći za ugrožene vrste, orla zmijara (Circaetus gallicus), sivog sokola (Falco peregrinus), prugastog orla (Aquila fasciata) i dr. Prugasti orao je na području PP Velebit u 2015. god. zastupljen sa samo 2 para.

\footnotetext{
${ }^{10}$ V. TUTIŠ - J. KRALJ - D. RADOVIĆ - D. ĆIKOVIĆ - S. BARIŠIĆ, 2013, 1-258.

${ }^{11}$ G. LUKAČ, 2011, 1-356.

${ }^{12}$ G. LUKAČ - M. STIPČEVIĆ, 1997, 11-60; G. LUKAČ, 2011, 1-356.

${ }^{13}$ G. LUKAČ - M. STIPČEVIĆ - R. HAUPT, 2003, 51-59; G. LUKAČ, 2002, 78-83.
} 
Tipična gnjezdarica kamenjarskih livada je jarebica kamenjarka (Alectoris graeca). U crnograbovim i crnobvorovim šumarcima se sreće strnadica cikavica (Emberiza cia) i mali djetlić (Dendrocopos minor). Sve tipove bukovih šuma nastanjuju rijetke vrste djetlića, kao planinski djetlić (D. leucotos), dok crna (Dryocopos martius) i siva žuna (Picus canus) nastanjuju bukove i crnoborove šumske sastojine. Troprsti djetlić (Picoides tridactylus) je zabilježen u sastojinama crnog bora na nadmorskoj visini od 950 do $1000 \mathrm{~m}$, odnosno na Babrovači u sjevernom Velebitu.

Redovito se gnijezdi u miješanim šumama bukve, jele i smreke kao i u čistim smrekinim i jelinim sastojinama sjevernog i srednjeg Velebita kao i na sjevernoj ličkoj padini. To područje nastanjuju i sove, mali ćuk (Glaucidium passerinum), ćuk batoglavac (Aegolius funereus) i planinska sova (Strix uralensis). Promatranja šarenog kulika (Charadrius morinellus) ukazuju na važnost visokoplaninskih livada u selidbi ove srednjoeuropske i sjevernoeuropske vrste prema afričkim zimovalištima. Neredovita zimovanja crvenokrilog zidarčaca (Tichodroma muraria) u kanjonima i na stijenama srednjeg i južnog Velebita dovedena su u vezu s posljednjim glacijacijama iz razdoblja pleistocena. Bogatstvo grmuša u pojedinim krškim biotopima ukazuje na polaganu sukcesiju i trend zaraštavanja južnih obronaka cijelog Velebita nakon što opada stočarstvo i brojnost stoke, kao i napuštanje ekstenzivnog stočarenja. Posebnost, raznolikost i bogatstvo ptičjeg svijeta uvjetovana je mediteranskim utjecajem i "prodorom" pojedinih mediteranskih vrsta u visokoplaninska područja Velebita, odnosno silaženjem pojedinih kontinentalnih vrsta u mediteranske dijelove parka prirode Velebit. Promjene i širenje areala pojedinih mediteranskih vrsta uočava se i u drugim dijelovima, npr. okolici Gračaca, gdje se u nizinskim dijelovima zadržava crnoglava strnadica (Emberiza melanocephala). Praćenjem područja gniježđenja brgljeza kamenjara (Sitta neumayer) u južnim dijelovima Velebita, pokazuju da se u 2014. god. započinje gnijezditi na južno eksponiranim stijenama vršne zone. Tako je pronađeno gnijezdo na stijenama ispod Buljme na nadmorskoj visini od oko 1300 m. Do 2014. god. redovito je gnijezdio u području Bojinca, Vidakovog kuka, Sopnja, Tulovih greda i Prezida. Utjecaj posjetitelja na raznolikost i bogatstvo ptica je prikazana za pojedine petrofilne vrste i usporedbom najposjećenijih dijelova južnog Velebita, u NP Paklenica i u kanjonima Velike

${ }^{14}$ G. LUKAČ, 2002, 78-83; G. LUKAČ, V. HRŠAK, 2005, 186-199.

${ }^{15}$ D. PERICA - D. OREŠIĆ, 1999, 1-50; D. PERICA - S. LOZIĆ, 2002, 5-29. 
i Male Paklenice ${ }^{14}$. Klimatska obilježja Velebita i periglacijalni reljef obrađuju Perica - Orešić i Perica \& Lozić. ${ }^{15}$

Glacijacija iz razdoblja pleistocena ${ }^{16}$ vjerojatno je danas ostavila traga u bogatstvu i raznolikosti ptica te utjecala na formiranje selidbenih pravaca $i$ kretanje ptica selica uz obalu i duž cijelog Velebita. Pružanje i položaj Velebita danas ima značajnog utjecaja na recentno širenje areala pojedinih ekspanzivnih vrsta, čime izravno utječe na rasprostranjenost pojedinih mediteranskih i kontinentalnih vrsta.

Bogatstvo i raznolikost ptica gnjezdarica pokazuje da je Velebit očuvana i krškim ekosustavima iznimno vrijedna planina. Ipak za većinu vrsta tek detaljnijim istraživanjima treba odrediti brojnost i stabilnost odnosno ugroženost populacija, posebno za pojedine vrste poput djetlića ${ }^{17}$ ili kokošaka, kao velikog tetrijeba i lještarke kojima brojnost opada sve intenzivnijom izgradnjom šumskih cesta ili krčenjem i sječom šuma. Posebno su ugrožene ptice grabljivice poput surog orla (Aquila chrysaetos) čija je brojnost procijenjena na svega 3-5 parova, na području koje bi moglo potencijalno zbrinuti najmanje 20 -ak parova.

Postavljanjem zatrovanih mamaca, pucanjem po pticama grabljivicama u lovištima ugrožene su i druge vrste ptica grabljivica: prugasti orao (A. fasciata), zmijar (Circaetus gallicus), škanjac osaš (Pernis apivorus), eja livadarka (Circus pygargus) i dr. Sove su također zastupljene vrstama poput ušare (Bubo bubo), jastrebače (Strix uralensis), planinskog (Aegolius funereus), malog ćuka (Glaucidium passerinum) i dr. Grmuše (rod Sylvia) su zastupljene u Velebitu s 8 vrsta koje svojim pjevom i raznolikošću ${ }^{18}$ mogu privući različite zaljubljenike u prirodu i promatrače ptica iz različitih dijelova Europe. Isto vrijedi i za sjenice (Paridae), koje su u Velebitu zastupljene s 8 vrsta.

\section{Literatura}

Mario BELIĆ - Goran ŠAFAREK, Nalaz šarenog kulika Charadrius morinellus na Velebitu, Larus, 48, Zagreb, 2002, 92-93.

${ }^{16}$ L. NIKLER, 1973, 109-112; S. BELIJ, 1985, 1-68; H. MALINAR, 1995, 55-60; D. PERICA, 1998, 1-251; I. VELIĆ - J. VELIĆ - I. VLAHOVIĆ - M. CVETKOVIĆ, 2014, 1-325; K. KRKLEC - D. DOMINGUEZ-VILLAR - D. PERICA, 2015, 188-195.

${ }^{17}$ G. GORMAN, 2004, 1-176.

${ }^{18}$ M. WIDMER, 2006, 4-6. 
Srđan BELIJ, Glacijalni i periglacijalni reljef Južnog Velebita, Posebna izdanja Srpskog geografskog društva, Beograd, 61, 1985, 1-68.

Colin J. BIBBY - Neil D. BORGES - David A. HILL, Bird Census Techniques. RSPB, University Press Cambridge, 1992,

Martin L. CODY, Habitat Selection in Birds. Academic Press Inc. Harcourt Brace Jovanovich Publishers. New York, 1985, 1-558.

Davor ĆIKOVIĆ - Sanja BARIŠIĆ, Izvještaj o prestenovanju. Rezultati prstenovanja ptica od 2003. do 2006. god., Bilten Hrvatske prstenovačke centrale, 3, 2009, 4-19.

Martin FLADE, Die Brutvogelgemeinschaften Mittel- und Norddeutschlands. Grundlagen für den Gebrauch vogelkundlicher Daten in der Landschaftsplanung. IHW Verlag, Echingen, 1994, 1-250.

Gerard GORMAN, Woodpeckers of Europe. A study of the European Picidae. Bruce Coleman, UK pp. 2004, 1-176.

Irena GRBAC - Jelena Kralj, Katalog zbirke ptica Hrvatskog prirodoslovnog muzeja, Natura Croatica, 17 (1), Zagreb, 2008, 1-226.

Ward J.M. HAGEMEIJER - Michael J. BLAIR, The EBCC Atlas of European Breeding Birds. Their Distribution and Abundance. T \& A.D. Poyser, London, 1997, 1-903.

Miroslav HIRTZ, Kritische Verbesserungen und Zusätze zum "Verzeichnis der Vögel der kroatischen Fauna". Ornithol. Jahrb. 23, 1912, 16-37.

Miroslav HIRTZ, Beiträge zur Kenntnis der Ornithofauna Croatica. Ornithol. Jahrb. 25, 1914, 1-2, 1-15.

Miroslav HIRTZ, Kritische Bemerkungen zur Monographie: Madarasz, Die Vögel Ungarns, Glasnik Hrvatskog naravoslovnog društva, 27, Zagreb, 1915, 74-90.

Miroslav HIRTZ, Kritische Beiträge zur Kenntnis der Vogelwelt Jugoslawiens, Glasnik Hrvatskog prirodoslovnog društva, 41-48, Zagreb, 1936, 161-230.

Marijana KATIĆ, Petrofilna ornitofauna kanjona Velike Paklenice. Diplomski rad. Biološki odsjek PMF-a, Sveučilišta u Zagrebu, Zagreb, 2002, 1-93.

Siegfried KLAUS, Situation der Rauhfusshühner in Thüringen, Naturschutzreport, 10, Thüringen, 1995, 11-21.

Siegfried KLAUS - Ulrich AUGST, Warum starb das Auerhuhn (Tetrao urogallus) im Elbsandsteingebirge aus? Naturschutzreport, 10, 1995, 109-123.

Jelena KRALJ - Sanja BARIŠIĆ - Davor ĆIKOVIĆ - Vesna TUTIŠ, Range Expansion of the Olive-tree Warbler Hippolais olivetorum along the Croatian coast., Acrocephalus, 33, (152/153), 2012, 105-107.

Kristina KRKLEC - D. DOMINGUEZ-VILLAR - Dražen PERICA, Depositional environments and diagenesis of a carbonate till from a Quaternary paleoglacier sequence in the Southern Velebit Mountain (Croatia). Paleogeogr.Paleoclimatol. Paleoecol. 436, 2015, 188-198.

Gordan LUKAČ - Mauricio STIPČEVIĆ - Robert CRNKOVIĆ - Denis BEM, Characteristics of habitat and distribution of Sitta neumayer Mich. (Aves) in Croatia and neighbouring areas, Natura Croatica, 1, Zagreb, 1992, 81- 91. 
Gordan LUKAČ, List of Croatian Birds. Spatial and temporal distribution, Fauna Croatica, Natura Croatica, 7, 3, Zagreb, 1998, 1-160.

Gordan LUKAČ, Bjeloglavi sup (Gyps fulvus Hablizl 1783) i njegova zaštita u Nacionalnom parku Paklenica. Studija, arhiva Uprave Parka, StarigradPaklenica, 1999, 1-34.

Gordan LUKAČ , Bjeloglavi sup, Hrvatski zemljopis, 46, Zagreb, 2000, 26-36.

Gordan LUKAČ, The Visitor Flows and the Bird Communities in the Paklenica National Park, Croatia (between 1997-2001). In A. Arnberger, C. Brandenburg, A. Muhar (ed.): Monitoring and Management of Visitor Flows in Recreational and Protected areas. Conferences Proceedings, Wien, 2002, 78-83.

Gordan LUKAČ, Ptice gnjezdarice šireg područja Nacionalnog parka "Paklenica", Paklenički zbornik, 2, Starigrad-Paklenica, 2004, 95-104.

Gordan LUKAČ, Popis vrsta ptica šireg područja NP "Paklenica", Paklenički zbornik, 2, Starigrad-Paklenica, 2004a, 105-112.

Gordan LUKAČ, Praćenje utjecaja posjetitelja na petrofilnu ornitofaunu NP "Paklenica", Paklenički zbornik, 2, Starigrad-Paklenica 2004b, 141-146.

Gordan LUKAČ, Aktivna zaštita o 55. obljetnici u NP "Paklenica", Paklenički zbornik, 2, Starigrad-Paklenica, 2004c, 151-154.

Gordan LUKAČ, Izumrle i ugrožene ptičje vrste u NP "Paklenica", Paklenički zbornik, 2, Starigrad-Paklenica, 2004d, 161-166.

Gordan LUKAČ, Zaštita krških ekosustava - KEC projekt u Hrvatskoj, Paklenički zbornik, 2, Starigrad-Paklenica, 2004e, 167-170.

Gordan LUKAČ, O širenju areala i statusu španjolskog vrapca (Passer hispaniolensis) u Hrvatskoj na početku 21. stoljeća, Paklenički zbornik, 2, Starigrad-Paklenica, 2004f, 113-122.

Gordan LUKAČ, Popis ptica Hrvatske. Fauna Croatica, Natura Croatica, 7, 3, Zagreb, 2007, 1-147, second edition.

Gordan LUKAČ, Ural Owl (Strix uralensis) in Croatia - their status and conservation. Nationalpark Bayerische Wald, Tagungsbericht - Heft 8, 2007a, 32-35.

Gordan LUKAČ, Atlas ptica Nacionalnog parka Paklenica. JU NP Paklenica i HPM, Zagreb, 2011, 1-356.

Gordan LUKAČ - Mauricio STIPČEVIĆ, Birds of National Park Paklenica, Croatia. Natura Croatica, 6, (1), Zagreb 1997, 11-60.

Gordan LUKAČ - Mauricio STIPČEVIĆ - Rainer HAUPT, Recent observations on the Griffon Vulture (Gyps fulvus) in the Paklenica National Park (Croatia). Acrocephalus, 24 (117), Ljubljana, 2003, 51-59.

Gordan LUKAČ - Zoran ŠIKIĆ, Smjernice za izradu plana upravljanja Nacionalnim parkom "Paklenica", Paklenički zbornik, 2, Starigrad-Paklenica, 2004, 155-160.

Gordan LUKAČ - V. HRŠAK, Influence of visitor numbers on breeding birds at the Paklenica National Park, Croatia. Oecologia (Bratislava), 24 (2), Bratislava, 2005, 186-199. 
Gordan LUKAČ - Tibor MIKUSKA, Bogatstvo i raznolikost ptičjeg svijeta nacionalnih parkova i parkova prirode Hrvatske. Zbornik povodom 20. godišnjice NP Krka. Šibenik, 5-8. 10. 2005, 2007, 357-370.

Gordan LUKAČ - Snježana VUJČIĆ-KARLO - Srećko BOŽIČEVIĆ - Zlatko MARASOVIĆ, Vodič kroz prirodnu i kulturnu baštinu Nacionalnog parka Paklenica. Astroida, Zagreb, 2007, 1-320.

Gordan LUKAČ - Snježana VUJČIĆ-KARLO - Wilibald STANI - Drago MARGUŠ, Ptice Nacionalnog parka Krka. Marguš, D. (ed.), JU NP Krka, Šibenik, 2015, 1-532.

Gordan LUKAČ - Snježana VUJČIĆ-KARLO - Marijan MILOVAC - Ivana ADŽIĆ, Breeding and winter distribution of Alpine Accentor (Prunella collaris) on the eastern coast of Adriatic Sea, Larus, 51, Zagreb, 2016, 7-16.

Hrvoje MALINAR, Tragovi pleistocenske oledbe na Velebitu u području Buljme. 1, 1995, 55-60.

Milan MAREK, Ornithologisches aus Zengg, Glasnik Hrvatskog naravoslovnog društva, 13, Zagreb, 1901,43-66.

Milan MAREK, Ornithologisches aus Zengg, Glasnik Hrvatskog naravoslovnog društva, 15, Zagreb, 1904, 31-61.

Milan MAREK, Ornithologisches aus Zengg, Glasnik Hrvatskog naravoslovnog društva, 16, Zagreb, 1905, 76-104.

Antun MAŠTROVIĆ, Die Vögel des Küstenlandes Kroatiens. I Bd. Institut für angewandte Zoologie in Zagreb, Zagreb, 1942, 1-192.

Antun MAŠTROVIĆ, Prilog poznavanju Charadriida F.N.R. Jugoslavije, Larus, 1, Zagreb, 1947, 36-56.

Leon NIKLER, Novi prilog poznavanju oledbe Velebita, Geološki vjesnik, 25, Zagreb, 1973, 109-112.

Dražen PERICA, Geomorfologija krša Velebita. Doktorska disertacija. PMF, Sveučilišta u Zagrebu Geografski odsjek, 1998, 1-251.

Dražen PERICA - Danijel OREŠIĆ, Klimatska obilježja Velebita i njihov utjecaj na oblikovanje reljefa, Senjski zbornik, 26, Senj, 1999, 1-50.

Dražen PERICA - Sanja LOZIĆ, Periglacijalni reljef na području Velebita, Geoadria, 7/1, Zadar, 2002, 5-29.

Joseph REICHHOLF, Ornithologische Studien in Jugoslawien. Mitt. D. Zool. Gesel. Braunau am Inn vol. 3 (1-2), 1977, 1-28.

Ervin RÖSSLER, Selidba ptica u Hrvatskoj i Slavoniji u g. 1919. i 1920, Glasnik Hrvatskog prirodoslovnog društva, 35, Zagreb, 1923, 142-167.

Dragutin RUCNER, Ptice hrvatske obale Jadrana, HPM i MRO, 1998, Zagreb, $1-311$.

Tim J. SHARROCK, The Atlas of Breeding Birds in Britain and Ireland. T. \& A. D. Poyser, Berkhamsted, 1976, 1- 477. 
Mauricio STIPČEVIĆ - Gordan LUKAČ, Survey of spreading and breeding range changes of the Red-rumped Swalow (Hirundo daurica) on Yugoslav territory, Larus, 43, Zagreb, 1991, 37-49.

Mauricio STIPČEVIĆ - Gordan LUKAČ, Status of tubenose seabirds Procellariiformes breeding in the eastern Adriatic, Acrocephalus, 22, Ljubljana, 2001, 9-21.

Goran SUŠIĆ - Dragan RADOVIĆ - Vlado BARTOVSKY, Znanstvena zbirka ptičjih svlakova Zavoda za ornitologiju JAZU, Zbornik radova Ornitologija u Hrvatskoj, Zagreb, 1988, 37-88.

Victor von TSCHUSI ZU SCHMIDHOFFEN, Zwei bemerkenswerte Erscheinungen des Jahres 1899. Ornithol. Jahrb. 1, 4, 1890, 66-68.

Vesna TUTIŠ - Jelena KRALJ - Dragan RADOVIĆ - Davor ĆIKOVIĆ - Sanja BARIŠIĆ, Crvena knjiga ptica Hrvatske. DZZP i MZOIP, Zagreb, 2013, 1-258.

Ivo VELIĆ - Josipa VELIĆ - Igor VLAHOVIĆ - Marko CVETKOVIĆ, Geološki vodič kroz NP Paklenica. JU NP Paklenica, Denona d.o.o., Starigrad-Paklenica 2014, 1-325.

M. WIDMER, Die Grasmücken schöne Augen, hinreissender Gesang. Ornis, 3, 2006, 4-9.

\section{THE BIRDS OF VELEBIT}

Summary

Studies of the ornithofauna of the southern part of Velebit have been running continuously since 1984. Part of the data is collected by the observation of the birds in various parts of the Paklenica National Park, as well as in parts of southern Velebit, from Veliko Libinje to Tulove Grede, Prezid and Crnopac. The area of central Velebit was studied from Bačić Kosa to Alaginac and Bačić Kuk in 2003, and occasionally in 2011 and 2012. The area of northern Velebit was visited around Zavižan, the botanical garden, part of the Premužićeva trail to Rossijeva Koliba, Lomska Duliba and Štirovača during 1988 and occasionally from 2007-2011. Birds were recorded at times of nesting, spring and autumn migrations as well as in winter. To date 271 bird species have been noted on Velebit.

165 species inhabit within the boundaries of the Paklenica National Park, 101 of which nest there. In the area of the Northern Velebit National Park 110 species have been noted. Today it can safely be said that 127 bird species nest on the Velebit mountain. This contribution contains a full list of the noted bird species, the category of endangerment, seasonal status, as well as an estimated number of nesting birds, i.e. migrations.

Keywords: birds of Velebit, nesting birds, richness and diversity of species, numbers, types of habitat, Velebit Nature Park Paklenica National Park, Northern Velebit National Park, karst 